\title{
Output and expected returns
}

\section{a multicountry study}

Rangvid, Jesper

Document Version

Final published version

Publication date:

2002

License

CC BY-NC-ND

Citation for published version (APA):

Rangvid, J. (2002). Output and expected returns: a multicountry study.

Link to publication in CBS Research Portal

\section{General rights}

Copyright and moral rights for the publications made accessible in the public portal are retained by the authors and/or other copyright owners and it is a condition of accessing publications that users recognise and abide by the legal requirements associated with these rights.

\section{Take down policy}

If you believe that this document breaches copyright please contact us (research.lib@cbs.dk) providing details, and we will remove access to the work immediately and investigate your claim. 
WP 2002-8

Output and Expected Returns - a multicountry study by

Jesper Rangvid

INSTITUT FOR FINANSIERING, Handelshøjskolen i København Solbjerg Plads 3, 2000 Frederiksberg C tlf.: 38153615 fax: 38153600

DEPARTMENT OF FINANCE, Copenhagen Business School

Solbjerg Plads 3, DK - 2000 Frederiksberg C, Denmark Phone (+45)38153615, Fax (+45)38153600 www.cbs.dk/departments/finance 


\title{
Output and Expected Returns - a multicountry study
}

\author{
Jesper Rangvid*
}

December 2002

${ }^{*}$ Department of Finance, Copenhagen Business School, Solbjerg Plads 3, DK-2000 Frederiksberg, Denmark. Phone: (45) 3815 3615, fax: (45) 3815 3600, and e-mail: jr.fi@cbs.dk.

The comments from Tom Engsted, Christian Lundblad, and Richard Sweeney as well as participants at the CEPR/NYSE ESSFM, the EEA meeting, the EFA meeting, the European FMA meeting, the X Tor Vergata conference, and seminars and workshops at the Aarhus School of Business, Copenhagen Business School, Lund University, and Norwegian School of Management are gratefully acknowledged. 


\begin{abstract}
This paper analyzes whether the price-output ratio (the $\widehat{p y}$-ratio) predicts real stock returns in twelve OECD countries. The $\widehat{p y}$-ratio is a ratio of a share price to a macroeconomic variable. Traditionally, either ratios of purely financial indicators, ratios of purely macroeconomic indicators, or ratios of macroeconomic indicators to wealth have been used to predict returns. However, if share prices are mean reverting, and thus contain a predictable component, and predictability of returns is related to the macroeconomic environment that ultimately determines the investment opportunities, a ratio of a share price to a macroeconomic variable could be believed to predict returns. The analyses reveal that the $\widehat{p y}$-ratios do indeed predict future stock returns in most of the countries that are studied.
\end{abstract}

Keywords: $\quad$ share prices, output of firms, return predictability

JEL-classification: F30, G15 


\section{Introduction}

Two fairly simple observations motivate the writing of this paper on the ability of the $\widehat{p y}$-ratio, an estimated ratio of the share prices of firms to the output of firms, to predict real stock returns: firms produce goods, and the quantities of goods that firms produce and sell are important determinants of firms' profits and value.

To understand these motivations more clearly, it is illustrative to scrutinize the underlying determinants of stock prices: Investors buy shares in firms in order to make capital gains on these shares or receive dividends from the firms. Therefore, the prices of shares are determined by the future dividends that the firms pay out discounted by the appropriate discount factors (the required returns on stocks), i.e. one may expect dividends in combination with prices to contain information about future required returns (Fama \& French, 1988 and Campbell \& Shiller, 1988a,b). However, as has been documented many times elsewhere (Campbell \& Shiller, 2001; Lettau \& Ludvigson, 2001a,b, 2002a; Ang \& Bekaert, 2001; and Goyal \& Welsh, 2002), the ability of dividend yields, dividends combined with prices, to predict stock returns has deteriorated considerably during the 1990s. But if dividend yields by definition are related to future stock returns, perhaps it will prove useful to dig one step further and instead examine the underlying determinants of firms' future profitability and value - the state variables. One of these state variables is the output of firms. Indeed, the idea in this paper will be that the long-run movements in share prices are influenced by the long-run movements in firms' output, the production of firms, and that combinations of prices and output can be used to predict returns in many countries.

The paper will examine how the macroeconomic side of the economy - measured by the output of firms - is related to share prices. As there is real growth in the economy, and therefore real growth in the series of output and share prices, it will be necessary to take into account the issue of non-stationary price and output series. To do so, the paper starts out by recapitulating the arguments of Campbell \& Shiller (1988b) who showed why a stationary ratio of share prices to dividends should predict returns and/or changes in dividends. The idea of this paper is now the following: Many economic models suggest that the non-stationary part of dividends is related to how much firms produce. When 
this is the case, the insights of Campbell \& Shiller (1988b) carry over to a situation where output of firms replaces dividends such that particular combinations of the otherwise nonstationary time series of share prices and output are cointegrated and thus stationary. The stationarity of these price-output combinations is then shown to imply that when current prices are higher than current output, investors expect firms to perform well in the future - produce much in the future - or discount rates to be low. In this way, a stationary ratio of stock prices to a macroeconomic variable, the output of firms, should predict returns and/or changes in real activity.

The first task in the empirical part of the paper will thus be to use cointegration methods to investigate whether the price-output ratios are stationary. The results are clear: output and share prices are cointegrated in all twelve OECD countries, and the estimated relations between share prices and output are thus stationary. This is in itself a noteworthy robust result given its international support. Regarding the estimates of the cointegration relations, it is reported that the coefficient to output is larger than one in all twelve countries. This latter finding is explained by allowing equity to be leverage as in Campbell (1986) and Abel (1999). In the remaining part of the paper, these estimated stationary relations will be called the $\widehat{p y}$-ratios.

The cointegration results are important because they support one implication of the theoretical framework of the paper, but they are perhaps even more important because they have implications for the specification of the predictive regressions. Indeed, Granger's Representation Theorem (Engle \& Granger, 1987) makes clear that if the non-stationary time series for output and share prices are cointegrated, they also have an error-correction representation implying that the cointegration residual must predict changes in either prices (returns) and/or changes in output. In a string of recent paper, Lettau \& Ludvigson $(2001 \mathrm{a}, \mathrm{b}, 2002 \mathrm{a}, \mathrm{b})$ have tested the predictive power of the $\widehat{c a y}$-ratio (a cointegration residual, too) for the US stock market - in this paper, the predictive power of the $\widehat{p y}$-ratios in twelve OECD countries is studied. ${ }^{1}$

\footnotetext{
${ }^{1}$ This is also a reason for the multicountry setting of the paper. Given empirical evidence that the US stock market has performed particularly well throughout the twentieth century, it is not obvious that evidence for the US carries over to other countries (Goetzmann \& Jorion, 1999). In order to examine the extent to which the results presented here are country specific, this paper provides evidence for twelve OECD countries.
} 
Having presented the cointegration analyses, the paper thus proceeds to answer its prime question: whether and how much the stationary price-output ratios can predict future stock returns. The most important result of the paper is that the $\widehat{p y}$-ratios are found to predict returns in most of the countries that are studied. Especially, the $\widehat{p y}$-ratios predict monthly returns in eight out of the twelve countries and they do so to a both an economically and statistically interesting extent with the right signs. For instance, it is found that the $\widehat{p y}$-ratios capture more than $30 \%$ of the variation of two-year cumulative returns in eight countries and more than $40 \%$ in five countries. And it is found that a one standard deviation increase in the $\widehat{p y}$-ratio corresponds to a 670 basis points change in for instance expected US annualized returns, i.e. variation in the $\widehat{p y}$-ratio is also economically important for the variation in real returns.

In order to analyze whether the $\widehat{p y}$-ratio contains information not already incorporated into more "standard" financial ratios and predictors, the explanatory power of the stationary $\widehat{p y}$-ratios is contrasted with that of other variables that are usually found to predict returns, such as the relative short interest rate, lagged returns, lagged dividend yields, lagged price-earnings ratios, and lagged changes in real activity. It turns out that the $\widehat{p y}$-ratio contains information not already incorporated into the control variables. Furthermore, the $\widehat{p y}$-ratio is the variable that significantly predicts stock returns in most countries. Because the paper contrasts the predictive power of the $\widehat{p y}$-ratios with that of the controls, the paper as a by-product provides international evidence on the ability of these traditional control variables to predict returns. It is found that the lagged relative interest rates as well as the lagged returns predict current returns in some countries, whereas both the dividend yields and the price-earnings ratios do generally not predict returns. These latter findings are in accordance with the ones reported in Ang \& Bekaert (2001).

To make sure that the results are robust towards different changes in the design of the analyzes, a number of additional tests are carried out:

- It is analyzed whether the $\widehat{p y}$-ratio predicts also changes in real activity. ${ }^{2}$ The overall result is that the $\widehat{p y}$-ratio is a strong predictor of the monthly changes in real activity

\footnotetext{
${ }^{2}$ As the paper investigates the relation between asset prices and future changes in real activity too, it is also related to the work of Fama (1990), Choi et al. (1999), Lamont (2001), and Liew \& Vassalou (2000).
} 
in all countries, whereas the $\widehat{p y}$-ratio does basically not predict long-horizon changes in real activity.

- A number of Monte Carlo analyses supplement the basic long-horizon OLS regressions, so as to control for possible biases in the long-horizon regressions (Hodrick, 1992 and Ang \& Bekaert, 2001), and the results remain robust.

- It is investigated whether the $\widehat{p y}$-ratios capture real returns also out-of-sample. The out-of-sample investigation covers the 1990s because returns during this period have elsewhere been shown to be difficult to predict using financial indicators such as the dividend yield (Goyal \& Welsh, 2002).

- The tests are performed for several different kinds of stock returns. It is found that the $\widehat{p y}$-ratios predict the capital gains from indices of industrial shares as well as the broader indices of MSCI shares, but also that they predict the capital gains plus dividends from the MSCI indices.

Eventually evaluating these and other tests, the $\widehat{p y}$-ratio ends up being an interesting candidate when trying to predict stock returns in an international setting.

The rest of the paper is organized as follows. The next section lays out the theoretical motivation for why the price-output ratio should predict returns. In section 3 , the data are discussed and in section 4 the analysis of cointegration between share prices and real output is conducted. Sections 5 through 6 deal with the extent to which returns and changes in real activity can be predicted on the basis of the deviations from the stationary $\widehat{p y}$-ratios as well as the controls. Section 7 presents the Monte Carlo study of the longhorizon cumulative-return regressions, and section 8 deals with the out-of-sample exercise. Section 9 shows that the $\widehat{p y}$-ratios capture not only the variation in returns on industrial share but also returns on the broader MSCI indices. Finally, a section is reserved for some interpretations before the paper is summarized and concluded. 


\section{The theoretical motivation}

The tests performed in this paper are probably best motivated by referring to the "dynamic Gordon model" developed by Campbell \& Shiller (1988b), and then seeing how the assumptions of the present paper fit into that framework. Campbell \& Shiller (1988b) start by rewriting the definition of stock returns $R_{t+1}=\frac{P_{t+1}+D_{t+1}}{P_{t}}$ as $p_{t}-d_{t}=-r_{t+1}+$ $\ln \left(1+\exp ^{p_{t+1}-d_{t+1}}\right)+\Delta d_{t+1}$, where $p_{t}$ is the log of the period $t$ price of the share, $d_{t}$ is the $\log$ of the dividends that the share pays out, $r_{t+1}$ is the $\log$ of $R_{t+1}$, and $\Delta$ is the difference operator. Take a first-order Taylor expansion around the mean of the log price-dividend ratio to the non-linear term $\ln \left(1+\exp ^{p_{t+1}-d_{t+1}}\right)$ and solve the resulting first-order difference equation forward, then impose the no-bubble constraint and take conditional expectations on both sides to finally write the price-dividend ratio as

$$
p_{t}-d_{t}=E_{t} \sum_{j=0}^{\infty} \rho^{j}\left(\Delta d_{t+1+j}-r_{t+1+j}\right)+\frac{k}{1-\rho},
$$

where $k=\ln \left(1+\exp ^{\overline{p-d}}\right)-\rho(\overline{p-d})$ with $\overline{p-d}$ as the mean log price-dividend ratio and $\rho=\frac{\exp ^{\overline{p-d}}}{1+\exp ^{\overline{p-d}}}<1$.

Equation (1) has strong implications. Knowing that it is based on the definition of returns, a log-linear approximation, and the ruling out of bubbles, (1) shows how it is possible to trace the expectations of stock market participants by examining the variation in the price-dividend ratio. If stocks trade at a higher price for given dividends, (1) shows that this must be so because stock market participants expect future discount rates (the required returns on the stocks) to be low if the growth in dividends is relatively constant.

As mentioned in the introduction, this strong implication of (1) has unfortunately turned out to be less clear in the recent data. Perhaps this is so because firms have started to buy back shares as an alternative to paying out dividends (Campbell \& Shiller, 2001), or perhaps this is so because firms have started investing their profits so as to increase firm value and thereby postpone the payments of dividends (Fama \& French, 2001). No matter the exact underlying reasons, however, the implication is that when valuing firms, investors not only look at the dividends that can be expected from the firms, but also look at the more fundamental underlying factors that determine the future possibilities of firms to pay out dividends whether the firms then decide to do so or not. One such 
variable could be the output of firms, what firms produce, and this is what is discussed in this paper. In terms of the equations, it is assumed that the non-stationary behavior of dividends comes from firms' output, $d_{t}=\gamma y_{t}$, with $y_{t}$ as output. In this formulation, $\gamma>0$ measures the extent to which equity is levered, as in Campbell (1986) and Abel (1999), such that $\gamma=1$ represents equity that is not levered and $\gamma>1$ represents levered equity. ${ }^{3}$ In this case, (1) can be written as

$$
p_{t}-\gamma y_{t}=E_{t} \sum_{j=0}^{\infty} \rho^{j}\left(\gamma \Delta y_{t+1+j}-r_{t+1+j}\right)+\frac{k}{1-\rho} .
$$

Equation (2) illustrates the basic idea of this paper: Variation through time in the price-output ratio, the left-hand side of (2), captures variation though time in expected returns if output is expected not to be very volatile.

There are at least two important implications of (2). The first, as mentioned, is that the current price-output ratio has implications for expected future returns. Consider for instance the case where $p_{t}<\gamma y_{t}$. As shown by (2), this can only occur if the sum of future returns is higher than that of output, i.e. returns are expected to increase or output changes to fall as compared to an initial situation where $p_{t}=\gamma y_{t}$. In other words, we cannot observe what investors actually expect, but we can see the price at which they trade stocks, and we can relate this price to the underlying fundamental. Thereby, it is possible to trace out the time variation in expected returns through the variation in the price-output ratio: when prices are high for given output, investors are willing to pay much for the stocks because they expect either the firms to perform well in terms of how much is produced or because investors expect future required rates of return to be low.

Another important implication of (2) is that if returns and changes in output are covariance stationary, the right-hand-side of $(2)$ is covariance stationary (because $\rho<1$ ). Consequently, the left-hand-side must thus be covariance stationary, too. This implies that in cases where the output series is a non-stationary series in levels and the price series is a non-stationary series in levels, these two series should cointegrate, i.e. the series $p_{t}-\gamma y_{t}$

\footnotetext{
${ }^{3}$ Campbell (1986) and Abel (1999) study endowment economies in which consumption is equal to production. Campbell (1986) notices that a random payoff shock, uncorrected with log production, can be added to the relation between dividends and production, as $d_{t}=\gamma y_{t}+v_{t}$, without changing the formulas for the risk premiums in the economy that he considers. Furthermore, Campbell (1986) explicitly considers both stationary and non-stationary processes for consumption/production.
} 
should be stationary. As is probably well-known, one of the implications of cointegration between two otherwise non-stationary time series is that the two time series are subject to the same shock with a permanent effect and thus have a tendency to follow the same long term growth path. In our case it will be the same shock with a permanent effect (for instance a productivity shock) that causes the non-stationary behavior of both the level of prices and the level of output. ${ }^{4}$ Of course, temporary shocks can cause deviations between the current levels of prices and output. If for instance a temporary shock causes the current level of prices to be above that of output, cointegration implies that prices over time will revert to the level consistent with the permanent trend in output, i.e. also from a purely statistical point of view, cointegration implies that deviations from the stationary cointegration relation $p_{t}-\gamma y_{t}$ can be used to predict returns and/or changes in output. This adjustment to a temporary disturbance is the essential implication of Granger's Representation Theorem for cointegrated variables (Engle \& Granger, 1987)

Finally, it is sensible to discuss the working assumption that the non-stationary behavior of dividends comes from firms' output. ${ }^{5}$ First, in models where aggregate output from the firms in the economy is perishable and produced without costs, such as in the endowment economy of Campbell (1986), all output is distributed in terms of dividends to the consumers, i.e. aggregate output is equal to aggregate dividends which are then again equal to aggregate consumption when - as Abel (1999) emphasizes - equity is not levered and thus $\gamma=1$. On the other hand, when equity is levered, the owners of the stocks receive more in dividends than what is backed up by production, and $\gamma>1$ as shown in Campbell (1986) and Abel (1999). Second, when there is a storage technology in the economy, agents can save and thus do not have to consume all output produced

\footnotetext{
${ }^{4}$ Beveridge \& Nelson (1981) showed how any non-stationary time series could be decomposed into a permanent and a temporary component. As cointegration means that a linear combination of nonstationary series is stationary, the implication must be that the non-stationary components cancel out by the linear combination of the series, i.e. the two series are subject to the same shock with a permanent effect.

${ }^{5}$ In addition to the discussion in the main text, notice also that this way of assuming a linkage between two underlying non-stationary theoretical variables is not unheard of when taking stylized theoretical models to data. For instance, Lettau \& Ludvigson (2001a) "assume that the non-stationary behavior of human capital comes from aggregate labor income" in order to find an observable variable for human capital in their empirical implementation of the consumption-wealth ratio of Campbell (1993).
} 
every period, and firms can invest and thus do not have to pay out all output in terms of dividends every period, i.e. dividends, consumption, and output do not have to be equal every period even if equity is not levered. To give just one example of this latter approach, in the stylized general equilibrium model of Balvers et al. (1990) the profit function subject to which the representative firm maximizes its object function is $d_{t}=y_{t}-i_{t}$, where $i_{t}$ are investments that are stationary because they represent the change in the capital stock, i.e. if $y_{t}$ is non-stationary, the non-stationary behavior of dividends will come from firms' output.

In summary: There are reasons to believe that the price-output ratio should predict returns as well as changes in real activity, and there are reasons to believe that output and share prices are not related one-to-one if equity is levered. However, these discussions and hypotheses are of course only interesting up to the point that they are somehow supported by the empirical evidence. The rest of this paper will examine whether this is the case.

\section{Data}

Twelve developed economies are studied in this paper. These economies are the G-7 countries, the Benelux countries, and the Scandinavian countries, i.e. Belgium, Canada, Denmark, France, Germany, Italy, Japan, Netherlands, Norway, Sweden, UK, and US. The sample period is the post Bretton Woods period, and the first sample observation is generally January 1973 and the last observation is generally December 2001. Data are sampled at a monthly frequency.

The two most important series in the analysis are the series of firms' output and share prices. The series for the output of firms were drawn from the Main Economic Indicators data base of the OECD, as this database provided reliable series for all the countries spanning a sufficient sample period. The series are given by the seasonally adjusted output of firms in the industrial sector. When using industrial output, the share prices should be those of firms in the industrial sector, too and they were drawn from the International Financial Statistics (IFS) data base of the IMF (IFS line 62). As the share price series are nominal whereas the indices of firms' output are real, the share price series were deflated with the consumer price indices of the relevant countries (IFS line 64), 
i.e. the same source (IFS) is used for both the share price series and the consumer price series. In the following, $p_{t}$ denotes the log of the real share price index in a given country, $y_{t}$ denotes the $\log$ of the industrial production series in a country, $r_{t}$ denotes real returns (the first order change in $p_{t}$ ), and $\Delta y_{t}$ denotes the first order change in log real activity. ${ }^{6}$

Furthermore, a set of control variables that are often reported to predict stock returns are used. Especially, the list of control variables includes lagged returns, lagged changes in real activity, a lagged relative short interest rate ( $r r e l)$, the lagged dividend yields $(d y)$, and the lagged price-earnings ratios $(p e)$. The choice of these variables was guided by the literature on return predictability (for surveys, see Ferson, 1995 and Campbell, 2000) and correspond to the variables used by e.g. Lamont (1998), Lettau \& Ludvigson (2001a) and Ang \& Bekaert (2001). The dividend yields and price-earning ratios were taken from Datastream (as IFS does not provide such series) and are those pertaining to the "General Industrials" in each country. The short interest rates used to create the relative interest rates are either the money market rates (IFS line 60b) or the treasury bill rates (IFS line 60c) depending on availability in the sense that the series with the longest available sample was chosen. ${ }^{7}$ All series were drawn from Datastream.

Table 1 provides the annualized means, the annualized standard deviations, and the first order autocorrelation coefficients of the variables that are used. Comparing the statistics for the series of real returns with those of the series for the changes in real activity, a couple of "stylized" facts appear: the average real returns on stocks generally

\footnotetext{
${ }^{6}$ To give a perspective on the robustness of these choices, section 9 of the paper summarizes results from tests for predictability using the broader MSCI indices. Using the broader MSCI indices, it can be investigated whether industrial production acts as a state variable and thus affects not only returns on industrial shares but also returns on other shares included in the broader MSCI indices. It turns out that the $\widehat{p y}$-ratios capture the future variation in the MSCI returns, too.

${ }^{7}$ It is noted that even if standard economic theory with respect to the time series properties of real interest rates and inflation would lead one to suspect these variables to be stationary (and thus that nominal interest rates are stationary too), nominal interest rates are often found to be non-stationary when analyzing particular sample periods, and indeed they were also found to be non-stationary in the samples studied in this paper. Actually, it has become standard to control with the relative interest rate (the current interest rate minus its one-year backward moving average); a stochastically detrended, and thus stationary, time series. For instance, Campbell (1991), Hodrick (1992), Lamont (1998), Lettau \& Ludvigson (2001a), and Santos \& Veronesi (2001) all use the relative interest rate as a control variable.
} 
are only a little higher than the average real growth in industrial production, but real stock returns are much more volatile. During the whole period, average real growth in industrial output has been between 1.1 percentage (UK and Belgium) and 2.5 percentage (Denmark), with an average for all countries equal to 1.95 percentage, whereas the average annual growth rate of share prices has been between 0.03 percentage (Japan) up to impressive 7.5 percentage (Sweden), with an average for all countries equal to 2.82 percentage. These means can be compared to the annualized standard deviations of real growth between 3 and 15 percentage (average for all countries equal to 7.33 percentage) and a standard deviation between 13 and 29 percentage for real returns (average for all countries equal to 19.50 percentage).

Regarding the persistence of returns and changes in real activity, it is noticed that the first order autocorrelation of real growth is negative in all countries (except US) whereas the first order autocorrelation of returns is generally positive. Furthermore, the persistence of changes in real output is generally higher than that of real returns, as the first order autocorrelations of returns are generally somewhat lower (in absolute value) than those of the changes in real activity.

Finally, the persistence of the control variables is generally high, especially when compared to the persistence of real returns and changes in real activity. Where the first order autocorrelation coefficients do not exceed 0.34 for the return series and 0.46 for the real activity series, they are all exceeding 0.88 for both the price-earnings ratios and the dividend yields, and many are even higher than 0.95, i.e. very close to unity. The relative interest rates are also persistent, though the autocorrelation coefficients are not as high as for the price-earnings ratios and the dividend yields.

\section{Cointegration tests}

The first restriction that the model in (2) places on the empirical behavior of the series for output and share prices is that these two series are driven by the same common stochastic trend and thus only differ by a stationary disturbance, the deviation from the estimated cointegration relation. The second hypothesis that seems relevant to test is whether the cointegration coefficients differ from unity or not. In order to tests these hypotheses, 
this paper uses in particular the multivariate tests of Johansen $(1988,1991)$. Below the intuition of the Johansen tests is presented. ${ }^{8}$ The tests are based on a VAR-model written in its error-correction form

$$
\Delta Z_{t}=\mu^{\prime}+\Pi Z_{t-1}+\sum_{i=1}^{k-1} \Gamma_{i} \Delta Z_{t-i}+\nu_{t},
$$

where $Z_{t}=[y, p]_{t}^{\prime}$ is the $n$-dimensional (here; $n=2$ ) vector of variables in the $\operatorname{VAR}(k)$ model, $\mu^{\prime}$ is a vector of constants, $\Gamma_{i}$ are coefficient matrices, and $\nu_{t}$ is the $n$-dimensional vector of residuals. The cointegration properties of the model are described by the matrix $\Pi$, the rank of which can be denoted by $r_{z}$. It turns out to be useful to decompose the matrix $\Pi$ as $\Pi=\alpha \beta^{\prime}$ where each of these new matrices is of dimension $n \times r_{z}$. In this formulation, $\beta^{\prime} Z_{t}$ are the stationary linear combinations of the otherwise non-stationary variables contained in $Z_{t}$, i.e. $\beta$ contains the $r_{z}$ cointegration vectors.

Three cases are relevant to consider: $(i)$ if the rank of $\Pi$ is equal to zero, all the time series in the VAR are non-stationary but do not cointegrate; $(i i)$ if $\Pi$ is a full-rank matrix, i.e. the rank of $\Pi$ equals the number of time series in the $V A R$, all time series in the VAR are stationary, and finally (iii) if the rank of $\Pi$ is reduced but different from zero, the $V A R$ system in levels is non-stationary and the number of cointegration relations equals the rank of $\Pi$. Based upon the fact that the rank of any matrix equals the number of characteristic roots that are different from zero, Johansen $(1988,1991)$ gives two likelihood ratio tests for the number of roots that are statistically different from zero. The $\lambda_{\text {Trace }}$ tests the null of at most $k$ cointegration vectors against the alternative of a stationary system, i.e. that the matrix $\Pi$ has full rank, and the $\lambda_{\max }$ tests the null of at most $k$ cointegration vectors against the alternative of $k+1$ cointegration vectors. When actually determining the number of cointegration vectors, a sequential testing strategy is used. First, the hypothesis of $r_{z}=0$ is tested against the alternative. If this test is rejected, the hypothesis of at most one cointegration vector, $r_{z} \leq 1$, is tested against the alternative hypothesis, and so forth until the hypothesis of $r_{z} \leq n-1$ is tested against $r_{z}=n$; $\mathcal{H}\left(r_{z} \leq n-1 \mid r_{z}=n\right)$. When a particular hypothesis cannot be rejected, the sequential testing procedure stops and the number of cointegration vectors has been found.

\footnotetext{
${ }^{8}$ Readers familiar with this way of testing for cointegration can without loss of continuity skip this description.
} 


\subsection{The results}

Table 2 presents results from the $\lambda_{\max }$ and the $\lambda_{\text {Trace }}$ tests for cointegration in each of the twelve countries. In the "Properties of $\widehat{\beta}^{\prime}$ " columns, the estimates of the coefficient on share prices from the $V A R \mathrm{~s}$ are presented (in the " $-(1 / \widehat{\gamma})$ " column $)^{9}$ together with $V A R$-based tests of whether this coefficient is equal to one, i.e. whether there is a oneto-one cointegration relation between share prices and real activity, in the " $\widehat{\beta}^{\prime}=[1,-1] "$ column. The null hypothesis in these last tests is that the series are stationary series and the tests are $\chi^{2}$-distributed with one degree of freedom.

The table also provides two univariate unit root tests and two Horvath \& Watson (1995) tests for each country. In the first of these tests (in the " $\widehat{\beta}^{\prime}=[1,-1 / \widehat{\gamma}]$ ” columns), the estimates of the cointegration coefficients on the share prices (as reported in the " $-(1 / \widehat{\gamma}) "$ column $)$ are imposed. These tests thus investigate whether series $p_{t}-\gamma y_{t}$ are stationary. In the second of these tests (in the " $\widehat{\beta}^{\prime}=[1,-1]$ " columns), it is investigated whether the "pure" price-output relations are stationary, i.e. whether the series $p_{t}-y_{t}$ are stationary. The null hypothesis in these tests is that the series are non-stationary series. The univariate tests are the standard Philips-Perron tests. The advantage of reporting also univariate Philips-Perron tests is that the Philips-Perron tests are designed to take into account possibly unknown serial correlation or heteroscedasticity remaining in the series. ${ }^{10}$ The use of the Horvath \& Watson (1995) tests is inspired by Lamont (1998). Lamont (1998) has problems in finding cointegration with unitary coefficients between prices and dividends, and between dividends and earning, for the US and argues for the use of "more efficient" Horvath \& Watson (1995) tests. These tests are designed to efficiently look for known cointegration vectors. They can thus be used to test whether a known one-to-one ratio of prices to output is stationary or whether relations with the known estimates of

\footnotetext{
${ }^{9}$ One advantage of the Johansen tests is that the results of the tests are not sensitive to the choice of "dependent" variable in the tests. On the other hand, in a two-step Engle-Granger (1987) type regression, the results will be sensitive to the choice of whether $p$ is regressed on $y$ or $y$ is regressed on $p$ in the first step.

${ }^{10}$ The Johansen tests and the following Horvath \& Watson (1995) tests are all based on VARs with three lags. This was sufficient to take account of the autocorrelation in the residuals. The PP tests can thus be viewed as robustness checks. Notice also that because the Johansen-based estimates for $\gamma$ are used, there would be no difference between results from PP tests using either the series $p_{t}-\gamma y_{t}$ or the series $y_{t}-\frac{1}{\gamma} p_{t}$.
} 
the cointegration coefficients reported in the " $-(1 / \widehat{\gamma})$ " column imposed are stationary. The Horvath \& Watson (1995) tests evaluate whether the $p_{t}-\gamma y_{t}$ terms, respectively the $p_{t}-y_{t}$ terms, can be excluded from the right-hand side of a vector autoregressive system of $\Delta p$ and $\Delta y$.

The results are the following. Looking at the $\lambda_{\max }$ tests, it is seen that for all countries except Norway the hypothesis of no cointegration is rejected, whereas the hypothesis of at most one cointegration vector cannot be rejected for any country. Looking at $\lambda_{\text {Trace }}$ tests, these report one cointegration vector in seven countries. ${ }^{11}$ In order to give a further perspective on these results, the Philips-Perron tests and the Horvath \& Watson (1995) tests can be consulted. The results from these tests are very clear: The hypotheses that the series $p_{t}-\gamma y_{t}$ are non-stationary are rejected for all twelve countries, i.e. in all countries do real share prices and real activity share a common stochastic trend.

Concerning the estimated cointegration coefficients, these are all within the range $[-0.19,-0.64]$ implying that the degree to which equity is levered is between $\widehat{\gamma}=(1 / 0.64)=$ 1.56 and $\widehat{\gamma}=(1 / 0.19)=5.26$. It is interesting to test the hypothesis that $\widehat{\gamma}=1$ in which case equity is not levered. Looking at the $\beta^{\prime}=[1,-1]$ columns of Table 2 , it is seen that the hypotheses that the $\widehat{\gamma}_{\mathrm{s}}$ are equal to one are rejected in all countries using the tests based on the Johansen procedure. The hypotheses that the $p_{t}-y_{t}$ series are nonstationarity cannot be rejected in any country except Canada when using the univariate PP tests. Finally, using the Horvath \& Watson (1995) procedure that looks for known one-to-one cointegration coefficients, none of these are unable to reject to null hypothesis of no cointegration. With this compelling evidence, 36 tests for unitary coefficients with 35 rejecting this, we should be safe to concluded that the share price and output series are cointegrated with a coefficient that is different from one. ${ }^{12}$

\footnotetext{
${ }^{11}$ Lütkepohl et al. (2000) systematically compare the properties of the $\lambda_{\max }$ and the $\lambda_{\text {Trace }}$ tests. They conclude that the power of the tests under local alternatives is very similar.

${ }^{12}$ Concerning the "long-run" relation between dividends and share prices, such results have previously been provided for the US in Froot \& Obstfeld (1991) and Barsky \& De Long (1993). Froot \& Obstfeld (1991) explain they findings by allowing for intrinsic bubbles in asset prices. These bubbles imply that prices can remain well above their fundamental value "forever" without a tendency to burst - an implication that Froot \& Obstfeld (1991) actually themselves deem "difficult to believe". Barsky \& De Long (1993) explain their findings by allowing growth rates of dividends to be non-stationary - an assumption Bansal \& Lundblad (2002) argue is hard to find economically plausible. Extending on the work of Barsky \& De
} 
As the final issue, consider the time series properties of the $p_{t}-\left(\frac{1}{\gamma}\right) y_{t}$ series. In the "Summary statistics" column of Table 2, the means and standard deviations of the $\widehat{p y}$-ratios are shown together with their first-order autocorrelation coefficient. The most important aspect to notice from these statistics is that even when the series are all stationary they are still somewhat persistent, i.e. stationary series may well have large first-order autocorrelation coefficients; the question posed in cointegration tests is whether the autocorrelation coefficients are statistically distinguishable from one - and they are in the countries analyzed here, as the many different tests revealed.

\section{Predicting monthly returns and changes in real activity}

As mentioned, cointegration of two time series implies that shocks to the estimated cointegration relation in this period can be used to predict future short run changes in the prices and/or output. Two questions arise: $(i)$ does the $\widehat{p y}$-ratio cause changes in both output and share prices and $(i i)$ does the $\widehat{p y}$-ratio contain information not only about the change in prices and/or output over the next period, but also over several periods? The following sections deal with these questions.

To evaluate the predictive content of the $\widehat{p y}$-ratios, the analysis proceeds in two steps. First, monthly versions of the predictive regressions are run, after which it is evaluated whether the $\widehat{p y}$-ratio contains information about long-horizon returns and changes in real activity also. The reason for separating between the monthly regressions and the longhorizon regressions is that the monthly regressions are free from potential complications arising from the use of the overlapping observations that result from the creation of the long-horizon returns - an issue that will be dealt with in detail in the section on longhorizon regressions.

Three kinds of basic regressions were run. Model 1 where the dependent variable, this being either this period's return or change in real activity, was regressed on a constant

Long (1993), Bansal \& Lundblad (2002) show how the price-dividend ratio will be volatile if shocks to growth rates are persistent but stationary. The model of Bansal \& Lundblad (2002) does not generate a "long-run" cointegration coefficient to the fundamental that differs from one, however, as it is the pricedividend ratio (the one-to-one relation between prices and dividends) that Bansal \& Lundblad (2002) show to be volatile. 
and the lagged $\widehat{p y}$-ratio only

$$
x_{t}=\kappa+\varphi \widehat{p y}_{t-1}+\varepsilon_{t}^{1},
$$

with $x_{t}$ indicating either the returns or the changes in real activity, $\kappa$ is a constant, and $\varphi$ is an estimated regression coefficient. In Model 1 , the $\widehat{p y}$-ratio is thus examined independently of any other factors. In Model 2, returns or changes in real activity were regressed on the lagged controls only, i.e. excluding the $\widehat{p y}$-ratio

$$
x_{t}=z_{t-1}^{\prime} \Psi+\varepsilon_{t}^{2},
$$

where $z_{t-1}=\left(1, \Delta y_{t-1}, \text { rrel }_{t-1}, d y_{t-1}, p e_{t-1}, r_{t-1}\right)^{\prime}$ is the vector of controls and $\Psi$ contains the estimated parameters. In model 2, the predictive power of the controls alone is thus examined. In the final Model 3, it was then examined whether the $\widehat{p y}$-ratio retained its possible predictive power when tested together with the controls, i.e. the full model takes the form

$$
x_{t}=z_{t-1}^{\prime} \Psi+\varphi \widehat{p y}_{t-1}+\varepsilon_{t}^{3} .
$$

\subsection{The results}

Table 3 contains the results from the estimations of models 1, 2, and 3 where the dependent variables are the monthly real returns, whereas Table 4 reports the results from the predictions of monthly changes in real activity. The tables present the parameter estimates with the $t$-statistics below and the $\bar{R}^{2}$ s with the associated $F$-tests below. The $t$-statistics and $F$-tests are based on Newey-West (1987) autocorrelation and heteroscedasticity consistent standard errors.

5.1.1 Returns. Concentrating on the estimations of Model 1, the most important result is probably that the $\widehat{p y}$-ratios predict returns in eight of the twelve countries that are studied and, perhaps even more important, the $\widehat{p y}$-ratio is the variable that is statistically significant in the highest number of countries, as seen from Table 3. Indeed, the $\widehat{p y}$-ratio is statistically significant in eight countries, whereas the lagged returns are significant in seven countries and the relative interest rate is significant in six countries. 
The changes in the $\widehat{p y}$-ratio are also economically significant. The coefficient to the $\widehat{p y}$-ratio is, in those countries where it is statistically significant, from Table 3 seen to be estimated in the range 0.05 to 0.14 , i.e. a one percentage change in the $\widehat{p y}$-ratio leads to a 0.05 to 0.14 percentage change in monthly returns. Furthermore, Table 2 revealed that the monthly standard deviation of the $\widehat{p y}$-ratio was estimated to be between 6 percentage (France and Germany) and 22 percentage (Norway). To understand these numbers, consider a specific example. The standard deviation of the US $\widehat{p y}$-ratio is 9.3 percentage, and the coefficient to the $\widehat{p y}$-ratio is 0.06 . This implies that a one standard deviation increase in the $\widehat{p y}$-ratio corresponds to a 670 basis points change in expected annualized returns, i.e. the $\widehat{p y}$-ratio tracks an economically important part of real returns. ${ }^{13}$

The signs to the coefficients to the $\widehat{p y}$-ratio are also right. From the theoretical model in (2), positive deviations from $y_{t}-\widehat{\gamma} p_{t}=\widehat{p y}_{t}$ should lead to increasing returns, and indeed the coefficients to the $\widehat{p y}$-ratios are all positive.

On average, deviations from the $\widehat{p y}$-ratio capture between one and three percentage of the total variation in next month's real returns. When analyzing monthly real returns, such numbers are typical (Lettau \& Ludvigson, 2001b), ${ }^{14}$ but as will be seen in the following sections, the $\widehat{p y}$-ratio captures a significantly larger part of the variation in future long-horizon returns.

How do the controls perform? First of all, it should be remembered that none of the controls are statistically significant in as many countries as the $\widehat{p y}$-ratio; the lagged returns and the lagged relative interest rates are closest. Concerning the lagged returns, all estimated parameters to $r_{t-1}$ are positive and in the interval between 0.15 and 0.35 in those countries where it is significant, and all coefficients to the lagged relative interest rates are negative and small in magnitude. The positive signs to the lagged returns capture the positive autocorrelation in returns also documented in Table 1 and the negative signs to the interest rates capture the covariation between movements in the business cycle and

\footnotetext{
${ }^{13}$ This can be compared to the roughly nine percent increase in the US S\&P 500 index that a one standard deviation increase in $\widehat{c a y}$ gives rise to (Lettau \& Ludvigson, 2001a).

${ }^{14}$ Remember also the second line from Fama \& French (1988): "The common conclusion, usually from tests on monthly data, is that the predictable component of returns, or equivalently, the variation through time of expected returns, is a small fraction (usually less than $3 \%$ ) of return variances".
} 
expected returns as suggested by for instance Fama \& French (1989). ${ }^{15}$ Finally, it should be stressed how the dividend yields and the price-earnings ratios do not systematically predict returns. This corresponds to the international findings reported in Ang \& Bekaert (2001), and for the US only such results have been reported by Goyal \& Welsh (2002) and in the papers by Lettau \& Ludvigson.

5.1.2 Changes in real activity. The $\widehat{p y}$-ratio can be expected to predict real returns, but it can also be expected to predict changes in real activity. More specifically, (2) reveals that positive deviations from $\widehat{p y}_{t}=y_{t}-\widehat{\gamma} p_{t}$ can be expected to lead to lower growth in real activity. Table 4 provides evidence on the ability of the $\widehat{p y}$-ratio to predict next month's changes in real activity. The table is structured as Table 3, i.e. first the predictive power of the $\widehat{p y}$-ratio is studied on its own, then the predictive content of the controls is analyzed, and finally that of the full model. In some sense, the results provided in Table 4 with respect to the ability of the $\widehat{p y}$-ratio to predict changes in real activity are even stronger than the results for returns: the $\widehat{p y}$-ratio is a significant predictor of future changes in real activity in all twelve countries, the coefficient is in all countries estimated to be negative as expected, and the $\widehat{p y}$-ratios capture between two and six percentage of the variation in next month's changes in real activity. The finding that the $\widehat{p y}$-ratio predicts changes in real activity is interesting when compared to the findings of Lettau \& Ludvigson (2001a, 2002b). Where Lettau \& Ludvigson (2001a) find that their $\widehat{c a y}$ ratio does not predict future changes in consumption, Lettau \& Ludvigson (2002b) find that the $\widehat{c a y}$-ratio predicts future changes in the level of firms' investments. In the same spirit, Table 4 confirms that a ratio of the firms' share prices to their output predicts next month's output, i.e. the $\widehat{p y}$-ratio has something to say about the future performance of that part of the real underlying macroeconomy that has to do with the behavior of firms.

Even when the $\widehat{p y}$-ratio predicts changes in real activity in all twelve countries, the $\widehat{p y}$ ratio is not the most important predicting variable, as it was when predicting returns. The

\footnotetext{
${ }^{15}$ Higher interest rates are bad for the business cycle and thus for returns. To this, notice how the next section will show that there is little evidence of a relation between the relative interest rate this month and the changes in real activity over the next month. However, business cycles are multi-month phenomena and the long-horizon regressions, i.e. changes in real activity over several months, reveal that the relative interest rates are related to future changes in real activity over longer horizons.
} 
reason for this is to be found in the strong negative autoregressive component of changes in real activity. Actually, the $t$-statistics to the lagged changes in real activity are all very high (in most cases higher than five or six), and the lagged changes in real activity alone capture as much as 24 percentage of the variation in this month's real activity changes, as the results from the estimation of Model 2 for Netherlands show. It is important to notice, however, that the information contained in the $\widehat{p y}$-ratio is generally information that is not contained in the lagged changes in real activity or other controls as the $\bar{R}^{2} \mathrm{~s}$ generally increase when augmenting Model 2 with the $\widehat{p y}$-ratio.

Finally, it is noticed that none of the other controls (the lagged relative interest rate, the lagged dividend yield, the lagged price-earnings ratio, or the lagged returns) systematically predict future changes in real activity.

\section{Long-horizon regressions}

Fama \& French (1988) were first to advocate the use of long-horizon regressions to enhance the power of dividend yields to predict stock returns. Their argument was that monthly return regressions reveal only part of the picture, the reason being that if expected returns are autocorrelated, their variance will over time grow faster than the variance of unexpected, and thus without autocorrelation, returns. Therefore, the part of total return variation that can be attributed to expected return variation grows as the horizon is increased and one gets a better feel for the predictive power of any predictive variable by looking at the evidence from long-horizon regressions. Following these suggestions it has become standard to present long-horizon regressions when evaluating the performance of different predictive variables (Lamont, 1998; Lettau \& Ludvigson, 2001, 2002; and Santos \& Veronesi, 2001, to mention a few), and the general finding is that the extent to which predictive variables can be used to predict increases with the forecasting horizon.

In this section, results from such long-horizon regressions will be presented. In particular, Table 5 shows the results from estimating Model 1 through 3 with multi-period (quarterly, yearly, and two-year) returns or changes in real activity as the dependent 
variables, i.e. models such as

$$
\begin{aligned}
x_{t+K} & =\kappa+\varphi \widehat{p y}_{t-1}+\varepsilon_{t}^{1^{*}} \\
x_{t+K} & =z_{t-1}^{\prime} \Psi+\varepsilon_{t}^{2^{*}} \\
x_{t+K} & =z_{t-1}^{\prime} \Psi+\varphi \widehat{p y}_{t-1}+\varepsilon_{t}^{3^{*}},
\end{aligned}
$$

where $x_{t+K}$ is the sum of the monthly returns or changes in real activity over the next $K$ months, with $K=3,12$, or 24 , i.e. quarterly, annual or two-year returns or changes in real activity.

There are many parameters to be estimated in long-horizon regressions. In the multicountry study of this paper, this is particularly true: there are three horizons, there are two variables to be predicted for each country, there are twelve countries, and for each country there is between one and seven parameters to be estimated for each dependent variable. These would be too many parameter estimates to absorb. Therefore, in Table 5 , only the $\bar{R}^{2}$ s as summary statistics are presented together with their autocorrelation and heteroscedasticity consistent $F$-tests, but a discussion of the results concerning the individual coefficients is provided. ${ }^{16}$

\subsection{Returns}

In accordance with the findings of for instance Fama \& French (1988), Lamont (1998), Lettau \& Ludvigson (2001a, 2002a,b), and Santos \& Veronesi (2001), Table 5 reveals how the fractions of the variances of long-horizon returns that can be captured by the dependent variables generally increase with the horizon. But the story is more interesting than that.

First of all, notice how the $\bar{R}^{2}$ s in the Model $1^{*}$ regressions increase only in those eight countries where the $\widehat{p y}$-ratio is significant at a monthly frequency. ${ }^{17}$ In general, the long-horizon regressions do thus not change the conclusions concerning the countries in which the $\widehat{p y}$-ratio predicts returns. Furthermore, the extents to which future returns can be captured by the $\widehat{p y}$-ratios are noteworthy, especially when compared with the extents

\footnotetext{
${ }^{16}$ Of course, these results can be obtained upon request.

${ }^{17}$ Denmark is an exception to this general pattern as the $\bar{R}^{2}$ s increase when increasing the horizon even when the $\widehat{p y}$-ratio was not significant in the monthly regression.
} 
to which returns can be predicted with the more "traditional" controls. Simply taking the average of the $\bar{R}^{2}$ s from the estimates of Model $1^{*}$ for the returns, one sees that the $\widehat{p y}$-ratios capture $1,5,20$, and 30 percentage of the future variation in respectively the monthly, quarterly, annual, and two-year returns as compared to the 5, 3, 10, and 11 percentage of the variation in returns that the controls capture. This implies that in those countries where the controls are significant they capture in general a higher fraction of the variation in monthly returns (and Table 3 showed that it was the lagged returns that were responsible for this predictability), whereas the $\widehat{p y}$-ratios capture much more of the variation in long-horizon returns than does the combined effort of lagged returns, lagged dividend yields, lagged price-earnings ratios, lagged changes in real activity, and lagged relative interest rates.

Given the fact that stock returns were high during the 1990s, it would be interesting to evaluate whether the results presented so far are due to this particular period, or whether they are stable over time and prevail during an earlier subsample, also. To investigate this issue, the analyses were redone for the period between 1973 and 1991. The overall conclusion is that the ability of the $\widehat{p y}$-ratio to predict is robust across time and countries. In particular, the estimates of $\gamma$ were (with the estimates from Table 2 in parentheses to ease comparisons): Belgium 0.30 (0.26), Canada 0.80 (0.64), Denmark 0.51 (0.49), France 0.18 (0.19), Germany 0.31 (0.28), Italy 0.23 (0.24), Japan 0.35 (0.44), Netherlands 0.30 (0.22), Norway 0.46 (0.44), Sweden 0.20 (0.24), UK 0.38 (0.43), and US 0.39 (0.36), i.e. estimates close to those obtained over the whole sample. Furthermore, the ability of the $\widehat{p y}$-ratio to predict returns during the early subsample was found to be as good as the ability of the $\widehat{p y}$-ratio to predict during the full sample. Finally, for this subsample it was only in Germany and Sweden that returns could not be predicted by the $\widehat{p y}$-ratio, i.e. during the early subsample, the $\widehat{p y}$-ratio has something to say about future returns in ten out of the twelve countries being studied.

\subsection{Changes in real activity}

Turning to the predictions of changes in real activity over the longer horizons, the picture is basically the opposite of the one just reported for returns as there are only few countries for which an increase in the horizon is associated with increases in the $\bar{R}^{2}$ s when predicting 
with the $\widehat{p y}$-ratios only. On the other hand, there are clear tendencies of increasing $\bar{R}^{2}$ s when predicting with the control variables. The conclusion from these analyses is thus that there is international evidence that the $\widehat{p y}$-ratio predicts monthly changes in real activity as revealed through Table 4, but this predictive information erodes as the forecasting horizon is extended. On the other hand, where the lagged changes in real activity were strong predictors of this period's changes in real activity, as Table 4 also showed, it was found that the lagged changes in real activity loose their predicting power as the forecasting horizon is extended, and the single variable that predicts the future changes in real activity is the relative interest rate. ${ }^{18}$ Finally, these results were also reported if looking only at early subsample, i.e. the results are stable over time.

\section{Statistical issues with long-horizon regressions}

Subtle statistical issues arise when using long-horizon regressions as those in the previous section. Especially, when $k>1$, there are overlapping observations and the residuals of the regressions are no longer independent of each other thereby possibly biasing the different test statistics towards rejecting the null hypothesis of no predictability more often than it is true. ${ }^{19}$ In order to make a perspective on these issues, this section contains the results

\footnotetext{
${ }^{18}$ Actually, this is a potentially interesting finding as it adds to the extensive literature documenting the ability of the slope of the term structure to predict future changes in real activity and/or inflation, see for instance Estrella \& Hardouvelis (1991), Jorion \& Mishkin (1991), Plosser \& Rouwenhorst (1994), and Ang et al. (2002). Whether the relative interest rate contains information about future changes in real activity and/or inflation that is not already included in the term spread is for future research to evaluate.

${ }^{19}$ It is therefore comprehensible that the issue of whether long-horizon regressions actually increase the power of tests is a hotly debated one. For instance, Valkanov (2002) notices that a sum of I(0) variables, such as the sum of monthly returns used to generate the multiperiod returns, behaves asymptotically like an I(1) variable, even when the sum is no $\mathrm{I}(1)$ variable, reminding us of the effects that spurious regressions have on estimated coefficients, t-statistics, and $R^{2}$ s. On the other hand, Mark \& Sul (2002) carefully compare the small sample power of the tests for no predictability in short-horizon regressions with the power of the tests in long-horizon regressions and conclude that long-horizon based tests are better at detecting predictability than tests based on short-horizon regressions. Other relevant references on this issue would at least include Hodrick (1992), Ang \& Bekaert (2001), and Campbell (2001). This paper does not take a stand on the general discussion on whether long-horizon regressions increase the power of tests. Instead, the paper presents the following analysis of the specific results presented in the previous sections.
} 
from a number of simple Monte Carlo experiments on the specific settings of this paper. ${ }^{20}$

The design of the Monte Carlo studies is fairly standard. The experiments are based on the following restricted Vector AutoRegressive model estimated for each country

$$
\begin{aligned}
r_{t} & =\kappa_{r}+\varepsilon_{r, t} \\
\widehat{p y}_{t} & =\kappa_{p y}+\sum_{i=1}^{4} \delta_{i} \widehat{p y}_{t-i}+\varepsilon_{p y, t} .
\end{aligned}
$$

The first equation of the restricted $V A R$ embodies the null hypothesis that real returns are unpredictable and only differs from their unconditional means $\kappa_{r}$ by $\varepsilon_{r, t}$. This formulation of the Data Generating Process for the returns under the null of no predictability is standard and resembles the specification used by Hodrick (1992), Mark (1995), and Ang \& Bekaert (2001). To capture the persistence in the $\widehat{p y}$-ratios, four lags of the $\widehat{p y}$-ratios were included in these equations. These four lags were enough to take account of the autocorrelation. Define $\varepsilon_{t}=\left(\varepsilon_{r, t}, \varepsilon_{p y, t}\right)^{\prime}$ with $\Omega=E\left(\varepsilon_{t} \varepsilon_{t}^{\prime}\right)$ and call the estimates of the parameters $\left(\widehat{\kappa_{r}}, \widehat{\kappa_{p y}}, \widehat{\delta_{1}}, \widehat{\delta_{2}}, \widehat{\delta_{3}}, \widehat{\delta_{4}}\right)$. The experiment now proceeds as follows:

1. Simulate sequences of observations $\left\{r_{t}\right\}_{t=1}^{n+T},\left\{\widehat{p y}_{t}\right\}_{t=1}^{n+T}$, with $n=1000$ and $T=343$, i.e. sequences of sizes $n+T=1343$ from

$$
\begin{aligned}
r_{t} & =\widehat{\kappa}_{r}+\varepsilon_{r, t} \\
\widehat{p y}_{t} & =\widehat{\kappa_{p y}}+\sum_{i=1}^{4} \widehat{\delta}_{i} \widehat{p y}_{t-i}+\varepsilon_{p y, t},
\end{aligned}
$$

where each $\varepsilon_{t}$ is drawn from a bivariate normal distribution with mean zero and variance/covariance matrix $\Omega$. In starting up the autoregression for $\widehat{p y}$, use the unconditional sample means as starting values.

2. Drop the first 1000 observations of the simulated observations $\left\{r_{t}\right\}_{t=1}^{n+T},\left\{\widehat{p y}_{t}\right\}_{t=1}^{n+T}$, and regress $r_{t+K}$ on $\widehat{p y}_{t-1}$, for $K=1,3,12$, and 24, using the remaining 343 observations. ${ }^{21}$ Keep in mind the statistics of interest - in what follows only the $\bar{R}^{2}$ s are reported, but one could of course keep in mind all aspects of the regressions (coefficient estimates, $t$-statistics, adjusted $t$-statistics, and so forth).

\footnotetext{
${ }^{20}$ To save space, only the results from the predictions of returns by the $\widehat{p y}$-ratios are shown.

${ }^{21}$ The 343 observations correspond to the typical number of observations in the regressions reported in Tables 3 through 5 .
} 
3. Repeat steps 2 through 3 five thousand times.

These five thousand observations of the $\bar{R}^{2}$ s will form the empirical distribution of the $\bar{R}^{2}$ simulated under the null of no return predictability. The five and ninety-five and the one and ninety-nine fractiles of the empirical distributions are presented in Table 6 together with the means of the five thousand $\bar{R}^{2}$ s for each of the regressions. Two results stand out:

a) As expected, the long-horizon regressions are biased towards rejecting the null of no predictability when in fact there is no predictability, and the biases increase with the horizon as the means and the ninety-five and ninety-nine fractiles of the simulated distributions of the $\bar{R}^{2}$ s increase with the horizon.

But also, and this is much more important in terms of the purpose of this paper,

b) the $\widehat{p y}$-ratio remains a rather strong predictor of future long-horizon returns even after controlling for the potential bias in the regressions.

The result that the regressions are biased towards finding predictability when in fact there is none is not a new one. The results presented in Table 6 thus confirm previous results and extend them to other countries, i.e. what is perhaps "new" on this issue is that international evidence is provided. To be more specific: the true $\bar{R}^{2}$ is equal to $\left(1-\frac{R S S}{T S S} \frac{342}{341}\right)=-0.0029$, with the residual sums of squares $(R S S)$ being equal to the total sums of squares $(T S S)$ under the null hypothesis that the model does not capture any variation in the returns. In the simulations, around ten percent of the $\bar{R}^{2}$ s were equal to their correct value, whereas in the remaining approximately 90 percent there were too high $\bar{R}^{2}$ s, and at the 95 percent level, the typical $\bar{R}^{2}$ is between 0.163 (Sweden) and 0.22 (Japan) for the two-year cumulative returns.

However, and more important for this paper, Table 6 also provides some comfortable evidence with respect to the issue on whether the $\widehat{p y}$-ratio predicts long-horizon returns. The column $\bar{R}^{2}$ in Table 6 repeats the actually observed $\bar{R}^{2}$ s from the regressions presented in Tables 3 and 5 . Comparing the simulated $\bar{R}^{2}$ s with the actually observed ones, it is seen that for the eight countries where the $\widehat{p y}$-ratios were found to predict returns in Tables 3 
and 5 , the actually observed $\bar{R}^{2}$ s are well above the 99 percent fractiles. This implies that even at a very conservative confidence level, it seems safe to conclude that the $\widehat{p y}$-ratio has indeed statistical significant predictive power. Another way of recognizing this fact is to look at "bias-adjusted" $\bar{R}^{2}$ s. One way of adjusting for biases is to subtract the mean of the simulated statistic from its actually observed value (Mark, 95). Looking at the means of the simulated $\bar{R}^{2}$ s for the 24 months returns, it is seen that in general they are between 0.04 and 0.06 . As the actually estimated $\bar{R}^{2}$ s typically reach levels around, or in excess of, 0.30, a substantial amount of the variation in the long-horizon returns are actually captured by $\widehat{p y}$-ratio and is not due to a statistical bias. For instance, the US bias-adjusted $\bar{R}^{2}$ s would be $0.02,0.06,0.23$, and 0.35 for the monthly, quarterly, annual, and two-year returns. These numbers are still very much significant. ${ }^{22}$

\section{Out-of-sample forecasts}

The results presented in the previous sections have all been based on the full sample of observations. This makes much sense when taking into account the arguments presented in Inoue \& Kilian (2002) for the use of in-sample tests when searching for predictability in population. ${ }^{23}$ This being said, one would nevertheless often like to known whether a high $\bar{R}^{2}$ in-sample indicates predictability out-of-sample too. To investigate this issue, this

\footnotetext{
${ }^{22}$ One aspect about the experiments is worth mentioning. The estimate of $\gamma$ in a cointegration regression is "superconsistent", i.e. converges to its true value at a rate proportional to the number of observations in the sample and thus not at the normal rate proportional to the square root of the number of observations (Stock, 1987). This "superconsistency" of the estimates implies that the relevant statistics of the particular regressions (standard errors, $t$-statistics, $R^{2} \mathrm{~s}$, and so forth) are calculated for the given estimate of $\gamma$ and do not have to be adjusted to account for the use of a generated regressor, $\widehat{p y}_{t-1}$. This is also the way the Monte Carlo studies are set up in this analysis. However, in finite samples, the estimate of $\gamma$ can differ between the different draws in the Monte Carlo study even when the cointegration parameters converge fast to their true values. In the experiments presented here, these potential differences are assumed to be small for two reasons. First, the interest in the experiments is on the specific settings of this paper, i.e. what are the potential biases in the $\bar{R}^{2}$ s given the estimate of $\gamma$ as presented in Table 2? Second, it is argued to be outside the scope of this paper to present and discuss Monte Carlo studies of the estimates of $\gamma$.

${ }^{23}$ Inoue \& Kilian (2002) argue that because out-of-sample analyses are based on a splitting of the full sample into smaller sub-samples, out-of-sample tests suffer from lower power. As a result, in-sample tests can be better at detecting predictability in population.
} 
section compares the accuracy of out-of-sample predictions generated from the $\widehat{p y}$-ratio to the accuracy of out-of-sample predictions generated from a number of benchmark models.

Out-of-sample predictions are generally based on the estimation of the model over some base period including $T$ observations, forecasts are generated, the model is reestimated over the base period plus one observation, i.e. over the period including $T+1$ observations, forecasts are generated, and so forth. In the tests presented below, the base period covers the period from the first observation in 1973 through December 1990. This implies that the out-of-sample predictions are for the 1990s. The 1990s are deliberately chosen for the out-of-sample exercise as Ang \& Bekaert (2001), Goyal \& Welsh (2002), and Lettau \& Ludvigson (2001a) all report that the variation in real returns during this period is hard to capture by the use of more standard financial ratios. It is thus interesting to evaluate whether the $\widehat{p y}$-ratio does a better job in predicting out-of-sample during this period than do the financial ratios. ${ }^{24}$

In order to compare the forecasts from the different models throughout the 1990s, one needs a metric that measures the quality of the forecast in comparison to a benchmark model. Call the root-mean-squared error of the predictions from the unrestricted model that is investigated for $R M S_{U}$. It is common to compare the $R M S_{U}$ with the root-meansquared error of the forecasts generated from a restricted benchmark model $R M S_{R}$. This metric is generally called "Theil's $U$ " so that $U=R M S_{U} / R M S_{R}$. If $U<1$, the forecasts generated from the unrestricted model are thus more accurate than the forecasts generated from the restricted benchmark model. In order to judge whether the root mean squared errors of the restricted and the unrestricted models differ significantly from each other, the Harvey et al. (1997) modification to the Diebold-Mariano (1995) test statistic is used. Harvey et al. (1997) show that one of several advantages of their modified test statistic is that it is applicable to forecast horizons exceeding one period. This is relevant for this paper that looks at cumulative long-horizon returns, too. After calculating the Harvey

\footnotetext{
${ }^{24}$ Notice that both the estimates of the cointegration parameter as well as the estimates of the parameter of the predicting regressions are recursively updated when doing the out-of-sample predictions, i.e. the predictions are based only on information available when generating the predictions. Furthermore, given a base period from 1973 to 1991, the first estimations in the recursive procedure are based on relatively large samples (the smallest samples containing approximately 18 years of monthly observations) implying that the cointegration parameters should be estimated with a reasonable degree of consistency.
} 
et al. (1997) statistics, these can be compared to the critical values of the Student's $t$ distribution with degrees of freedom equal to the number of observations minus one.

Table 7 presents the results from evaluating the out-of-sample predictions from different forecasting models. Three unrestricted forecasting models were used: one where the $\widehat{p y}$-ratios are used to predict monthly, quarterly, annual, or two-year cumulative returns, one where the dividend yields are used to predict, and one where the price-earnings ratios are used to predict. The forecasts from these models are compared to the forecasts from a random walk with a drift. The table presents the Theil's $U_{\mathrm{s}}$, the associated $t$-statistics as well as the probability values that the $t$-statistics are significantly equal to zero, and thus that the forecasts from the models are not significantly better than those of a random walk with a drift.

Several results are noteworthy. Most importantly, Table 7 shows that the $U$-statistics are generally smaller than one when predicting out-of-sample using the $\widehat{p y}$-ratios whereas they are generally larger than one when using either the dividend yields or the priceearnings ratios to predict. This implies that the forecasts generated from the $\widehat{p y}$-ratios are generally better than those from a random with a drift out-of-sample, whereas the outof-sample forecasts generated from the dividends yields or the price-earnings ratios are generally worse than those generated from a random walk with a drift. This being said, it should be noted that even when the forecasts are generally better out-of-sample than the forecasts from the benchmark model, they are in many cases not statistically different from those of the benchmark model. ${ }^{25}$ Finally, the predictions one could generate using a random walk with a drift are better than the predictions one would generate using either the $\widehat{p y}$-ratios, the dividend yields, or the price-earnings ratios in Germany, Japan, and UK. The results for these last three countries are thus in accordance with the results presented in Tables 3, 5, and 6 that also revealed that the variation in real returns in these countries is difficult to capture.

\footnotetext{
${ }^{25}$ It is however interesting to notice however that in those cases where Theil's $U$ is significantly different from one when predicting using the $\widehat{p y}$-ratio $U<1$, whereas in those cases where Theil's $U$ is significantly different from one when predicting using the either the dividend yields or the price-earnings ratios $U>1$.
} 


\section{Other returns}

The underlying fundamental investigated in this paper is the production of firms in the industrial sector, and the previous sections have thus been concerned with predicting changes in the prices of shares issued by industrial firms. However, if industrial production is a state variable that determines the future investment opportunities in the economy, it seems reasonable to conjecture that industrial production should have something to say about future returns on the whole stock market and not only about the returns on industrial shares. This is the more challenging task for the $\widehat{p y}$-ratio that is investigated in this section. As a comprehensive measure of the returns on the different markets, the Morgan Stanley Capital Index (MSCI) were used. This section thus briefly presents results from analyses of whether $\widehat{p y}$-ratios using CPI-deflated MSCI indices as the measure of $p_{t}$ could be used to predict both the changes in the real MSCI price series (the capital gains) as well as the full returns consisting of both the capital gains and the dividend yields. ${ }^{26}$

Cointegration tests with the real MSCI indices as the $p_{t}$ series and industrial production as the $y_{t}$ series were performed. To save space, the cointegration results will only be commented briefly upon. Most importantly, industrial production and MSCI real share prices were cointegrated and the coefficients were different from one. ${ }^{27}$ The estimates of $\gamma$ were (with the estimates from Table 2 in parentheses): Belgium 0.19 (0.26), Canada 0.52 (0.64), Denmark 0.43 (0.49), France 0.18 (0.19), Germany 0.25 (0.28), Italy $0.25(0.24)$, Japan 0.41 (0.44), Netherlands 0.15 (0.22), Norway 0.88 (0.44), Sweden 0.21 (0.24), UK 0.25 (0.43), and US $0.38(0.36)$ and were all, with the exception of Norway, rejected to be equal to one, i.e. results that are in a broad sense very similar to the results obtained using the real share price series from the IFS.

Table 8 presents the results from tests of predictability of the changes in the real MSCI share prices and the MSCI returns including dividends. The table shows in the $\varphi$-rows

\footnotetext{
${ }^{26}$ From a statistical point of view, it is a more challenging task to predict both the capital gains and the dividends than predicting only the capital gains, as Granger's Representation Theorem only has implications for the changes in the share price series - not for the dividends that the particular stocks pay out.

${ }^{27}$ Using the Johansen tests, the evidence on cointegration was not strong in Denmark and Norway, however.
} 
the coefficient estimates with Newey-West (1987) autocorrelation and heteroscedasticity corrected $t$-statistics in parentheses below and the 95 percentage fractiles from simulated empirical distributions of the Newey-West (1987) autocorrelation and heteroscedasticity corrected $t$-statistics generated under the null of no predictability in squared brackets. The empirical distributions of the $t$-statistics were calculated as described in section 7 , i.e. 5000 Monte Carlo simulations of $\mathrm{AR}(4)$-equations for the $\widehat{p y}$-ratios and constant return equations were generated and then 5000 estimates of the predicting regressions were carried out. Ranked in increasing order, the $5000 t$-statistics from these regressions form the empirical distributions for the $t$-statistics. The $\bar{R}^{2}$ rows show the $\bar{R}^{2}$ s from the estimates of the predicting regressions using the $\widehat{p y}$-ratios based on MSCI share prices as predictors. Below the $\bar{R}^{2}$ s, the probability values from tests of the hypothesis that $\varphi=0$ are shown in parentheses and in squared brackets, the 95 percentage fractiles from the simulated empirical distributions of the $\bar{R}^{2}$ s generated under the null of no predictability are shown.

The results are very much in line with what was found in the previous tables based on IFS share prices. Essentially, the $\widehat{p y}$-ratio is able to capture a substantial part of the future variation in real stock returns in eight OECD countries, whereas it cannot capture the variation in real stock returns in Germany, Japan, Netherlands, and Sweden. Furthermore, the $\widehat{p y}$-ratio captures not only the variation in MSCI capital gains, but also a large part of the variation in the full returns. Concerning the simulated empirical statistics, the same pattern as in Table 6 is seen, i.e. the longer the forecasting horizon, the higher the simulated $\bar{R}^{2}$ s and $t$-statistics (even when the "true" $\bar{R}^{2}$ is equal to -0.003 and the "true" $t$-statistics is equal to 1.96), but also that the $t$-statistics and $\bar{R}^{2} \mathrm{~s}$ in Belgium, Canada, Denmark, France, Italy, Norway, UK, and US are well outside the simulated empirical 95 percentage fractiles. ${ }^{28}$ In summary, the $\widehat{p y}$-ratio can also capture a substantial part of the future variation in real MSCI capital gains and returns in many countries.

\footnotetext{
${ }^{28}$ As a by-product, Table 8 confirms the result of Ang \& Bekaert (2001) that the Newey-West (1987) corrections that are often used to guard against the autocorrelation that results from the summing of observations when calculating cumulative returns are not enough to eliminate all biases as these tests still reject the null of no predictability more often than they should.
} 


\section{Interpretations}

How can the results of this paper be interpreted? Why does the $\widehat{p y}$-ratio contain information about expected returns not already incorporated in financial ratios? This section proposes some brief answers to such kind of questions.

The first reason for the results of this paper is likely to be found in the implications of Miller \& Modigliani (1961) who showed that the amount of dividends that firms pay out can be completely disconnected from the true performance of firms. In theory, a firm can pay out any arbitrary level of dividends without influencing the value of the firm. This is not so with the production of firms. For production to occur, real economic activity that influences the value of the firm must take place. Furthermore, and in the same spirit, the output of firms is a more "clean" series than that of dividends in the sense that dividends are paid out infrequently (quarterly or annually) such that manipulations of the dividend series are necessary when looking at higher frequency returns (for instance monthly) whereas the output of firms is what it is. Perhaps most important, the empirical evidence has shown that there has been an increasing divergence between stock prices and underlying financial fundamentals during the 1990s (Shiller, 2000). ${ }^{29}$ As reported elsewhere (Campbell \& Shiller, 2001), the divergence between dividends and share prices was probably due to both a skyrocketing of the stock prices themselves as well as to the low dividends that have been paid out. Campbell \& Shiller (2001) explain this by the fact that firms increasingly pay out profits in terms of share repurchases instead of dividends due to the more favorable tax treatment of repurchases and Fama \& French (2001) report that firms that do not pay out dividends invest more in order to increase firm value and thereby capital gains that are taxed relatively favorably. Concerning earnings, Campbell \& Shiller (2001) argue that they can also be noisy measures of the true performance of firms, given the way for instance executive bonuses are treated in the financial reports. Finally, country dependent rules on how to deduct depreciations from the tax bills of

\footnotetext{
${ }^{29}$ Perhaps the declines in stock prices throughout 2001 and 2002 represent a return to "more normal times" (Campbell \& Shiller, 2001). The divergence between share prices and financial fundamentals throughout the 1990s has implied, however, that it has proven increasingly difficult to use financial ratios to predict stock returns as emphasized in Lettau \& Ludvigson (2001a), Ang \& Bekaert (2001) and Goyal \& Welsh (2002).
} 
firms can also cause earnings to become clouded measures of the profitability and future performance of firms.

Given these arguments, it is comprehensible why recent research has documented that the ability of financial ratios to predict returns has declined considerably during the $1990 \mathrm{~s},{ }^{30}$ and therefore reasonable to believe that the output of firms adds information about future returns not already captured by the more standard financial ratios.

One way to somehow summarize all this is provided in Figure 1 that shows the US dividend yield and the US $\widehat{p y}$-ratio throughout the sample period (the picture is typical for the other countries, too). The figure makes clear why the dividend yield has had only little to say about expected returns recently, and it makes clear why the $\widehat{p y}$-ratio has had something to say. Indeed, the graph shows that prices have been increasing much more than dividends since the 1980s, i.e. prices have during the last couple of decades showed only a weak tendency to revert to the level implied by the underlying dividends. On the other hand, the fluctuations in the $\widehat{p y}$-ratio have been fairly constant after approximately 1980, i.e. prices have shown a tendency to move along the same trend as output. In some sense, the intention with this paper has been to show that this visual impression is actually a statistically significant feature of the data in many countries.

\section{Summary and conclusion}

The first ratios that were used to predict stock returns were ratios of purely financial indicators, such as the price-dividend ratio, the price-earnings ratio, the dividend yield (Campbell \& Shiller, 1988a,b and Fama \& French, 1988, 1989), ${ }^{31}$ the dividend-earnings ratio (Lamont, 1998), and the ratio of a short interest rate to its historic moving average (Campbell, 1991 and Hodrick, 1992).

If it is argued that returns are predictable by financial ratios, one immediately faces

\footnotetext{
${ }^{30}$ Where Campbell \& Shiller (2001), Lettau \& Ludvigson (2001a,b, 2002b), and Goyal \& Welsh (2002) provide evidence for the US, Ang \& Bekaert (2001) report international evidence on the issue and find that the price-earnings ratios and the price-dividend ratios do not predict returns internationally whereas the short interest rate still is important. The importance of the interest rate for predicting real stock returns in the same twelve countries as those studied in this paper is confirmed by Rapach et al. (2002).

${ }^{31}$ Fama \& French (1988) cites Dow (1920) as the first to use the dividend yield to predict stock returns.
} 
the question of why returns are predictable. One answer could be that markets react to information that should not lead to movements in prices in an efficient market (Cutler et al., 1993). Another reason, however, could be that required returns and possibly risk aversion (Campbell \& Cochrane, 1999) change over the business cycle as the result of time-variation in the available investment opportunities. If this second explanation contains some truth, it seems reasonable to conjecture that the macroeconomic variables that ultimately determine the investment opportunities should contain information that can be used to predict returns, and indeed, Cochrane (1991) shows that the investment-capital ratio predicts returns, Lettau \& Ludvigson (2001a,b, 2002b) show that an estimated consumption-wealth ratio predicts returns, and Santos \& Veronesi (2001) show that the consumption-labor income ratio predicts returns.

The intuitive motivation for investigating whether the price-output ratio predicts returns is thus a simple one: If predictability of returns is related to the macroeconomic situation and financial ratios including stock prices predict returns because stock prices are mean reverting towards some fundamental, perhaps a ratio of stock prices to a macroeconomic variable predicts returns.

Given this motivation, the main body of the paper was concerned with the estimation of stationary price-output ratios and investigating how well such ratios could predict returns in twelve economies. In summary, the findings were that the estimated price-output ratios were stationary in all countries, the coefficient to prices was larger than one in all countries, the estimated price-output ratios predicted next month's change in real activity in all countries but not longer-term movements in real activity, and most importantly the $\widehat{p y}$-ratio captured a substantial proportion of the variation in future returns in most countries. The finding that the $\widehat{p y}$-ratio predicts returns seems to be robust and is there when looking at shorter samples, predicting out-of-sample, adjusting for biases in longhorizon regressions, looking at several kinds of stock returns, and all this in many countries.

These robustness tests notwithstanding, there are always additional features that could be addressed. Two extensions of the present paper especially come to mind. The first is a more "statistical" extension, the second is a more "economical" extension. Concerning the statistical extension, this paper has investigated whether the $\widehat{p y}$-ratios of the different individual countries could capture future returns in the individual different countries. This 
make much sense giving the literature that the present paper is mostly related to. For instance, Fama \& French (1988, 1989), Lamont (1998), and Lettau \& Ludvigson (2001a) all consider whether the variables they focus on predict returns in individual countries. Having the data from the different countries, however, one way to proceed in future work could be to form panels of the data and use panel-cointegration techniques to look for cointegration across countries and use panel-forecasting methods when predicting. An advantage of panel-regression techniques is that the power of the different tests increase (due to the higher number of observations used to calculate the different parameters and statistics). On the other hand, a disadvantage would be that information regarding the individual countries gets more clouded, and for this last reason, single-country regressions were performed in this paper.

Another extension to be mentioned here relates to the ever-interesting issue of market efficiency. Indeed, when the $\widehat{p y}$-ratios predict returns, one would in principle like to know whether this predictability is due to some form of irrationality or whether it can be explained by rational asset pricing. In order to investigate such issues, a full-fleshed asset-pricing model is needed. The "economic" extension of this paper could thus be to use the $\widehat{p y}$-ratios in more formal asset-pricing tests and see whether the $\widehat{p y}$-ratios can be used when trying to explain the cross-sectional distribution of stock returns as in for instance Lettau \& Ludvigson (2001c) who show how their $\widehat{c a y}$-ratio is able to capture a substantial part of the cross-sectional variation in US returns. Perhaps it would even be reasonable to cast such kind of asset-pricing tests within the framework of international asset pricing models (Harvey et al., 2002 and Dahlquist \& Sällström, 2002).

Given the results of the present paper, such issues could be interesting to pursue in future work. 


\section{References}

ABEL, Andrew B. (1999): "Risk premia and term premia in general equilibrium," Journal of Monetary Economics, 43(1), 3-33.

Ang, Andrew, And Geert Bekaert (2001): "Stock return predictability: Is it there?," manuscript, Columbia Business School.

Ang, Andrew, Monika Piazzesi, And Min Wei (2002): "What does the Yield Curve Tell us about GDP Growth?," manuscript, Columbia Business School.

Balvers, Ronald J., Thomas F. Cosimano, and Bill MacDonald (1990): "Predicting stock returns in an efficient market," Journal of Finance, 45(4), 1109-1128.

Bansal, Ravi, And Christian Lundblad (2002): "Market efficiency, asset returns, and the size of the risk premium in global equity markets," Journal of Econometrics, 109(2), 195-237.

BArsky, Robert B., AND BrAdFord De Long (1993): "Why does the stock market fluctuate?," Quarterly Journal of Economics, 108(2), 291-311.

Beveridge, Stephen, And Charles R. Nelson (1981): "A new approach to the decomposition of economic time series into permanent and transitory components with particular attention to the measurement of the business cycle," Journal of Monetary Economics, 7, 151-174.

Campbell, John Y. (1986): "Bond and stock returns in a simple exchange model," Quarterly Journal of Economics, 101(4), 785-803.

- (1991): "A variance decomposition of stock returns," Economic Journal, 101, 157-179.

(1993): "Intertemporal asset pricing without consumption data," American Economic Review, 83(3), 488-512.

— (2000): "Asset pricing at the millennium," Journal of Finance, 55(4), 1515-1567.

(2001): "Why long horizons? A study of power against persistent alternatives," Journal of Empirical Finance, 8(5), 459-491.

Campbell, John Y., And John H Cochrane (1999): "By force of habit: A consumption-based explanation of aggregate stock market behaviour," Journal of Political Economy, 107(1), $205-251$.

Campbell, John Y., And Robert J. Shiller (1988a): "Stock prices, earnings, and expected dividends," Journal of Finance, 43, 661-676.

(1988b): "The dividend-price ratio and expectations of future dividends and discounts factors," Review of Financial Studies, 1(3), 195-228. 
(2001): "Valuation ratios and the long-run stock market outlook: An update," NBER Working Paper, 8221.

Choi, Jongmo Jay, Shmuel Hauser, and Kenneth J. Kopecky (1999): "Does the stock market predict real activity: Time series evidence from the G-7 countries," Journal of Banking and Finance, 23(12), 1771-1792.

Cochrane, John H. (1991): "Production-Based Asset Pricing and the Link Between Stock Returns and Economic Fluctuations," Journal of Finance, 46, 207-234.

Cutler, David M., James M. Poterba, and Lawrence H. Summers (1989): "What moves stock prices?," Journal of Portfolio Management, 15(3), 4-12.

DAhlquist, Magnus, AND TORBJÖRn SÄLlström (2002): "An evaluation of international asset pricing models," mimeo.

Diebold, Francis X., and Roberto S. Mariano (1995): "Comparing predictive accuracy," Journal of Business and Economic Statistics, 13, 253-263.

Dow, Charles H. (1920): "Scientific stock speculation," The Magazine of Wall Street.

Engle, Robert F., And Clive W. J. Granger (1987): "Co-Integration and Error Correction: Representation, Estimation and Testing," Econometrica, 55(2), 251-276.

Estrella, A., AND G. HaRdouvelis (1991): "The term structure as a predictor of real activity," Journal of Finance, 46, 555-576.

Fama, Eugene (1990): "Stock Returns, Expected Returns and Real Activity," Journal of Finance, 45, 1089-1108.

Fama, Eugene, and Kenneth R. French (1988): "Dividend yields and expected stock returns," Journal of Financial Economics, 22(1), 3-25.

(1989): "Business conditions and expected returns on stocks and bonds," Journal of Financial Economics, 25(1), 23-50.

— (2001): "Disappearing dividends: changing firm characteristics or lower propensity to pay?," Journal of Financial Economics, 60(1), 3-43.

Ferson, WAyne (1995): "Theory and empirical testing of asset pricing models," in Handbook in Operations Research and Management Science, ed. by R. Jarrow, V. Maksimovic, and W. T. Ziemba, vol. 9, chap. 5, pp. 145-200. Elsevier Science Publishers B.V.

Froot, Kenneth A., And Maurice Obstfeld (1991): "Intrinsic bubbles: The case of stock prices," American Economic Review, 81(5), 1189-1214. 
Goetzmann, William N., And Phillipe Jorion (1999): "Global stock markets in the twentieth century," Journal of Finance, 54(3), 953-980.

Goyal, Amit, And Ivo Welch (2002): "Predicting the equity premium with dividend ratios," NBER Working Paper, 8788.

Harvey, Campbell R., Bernard Dumas, and Pierre Ruiz (2002): "Are Correlations of Stock Returns Justified by Subsequent Changes in National Outputs?," mimeo.

Harvey, David, Stephen Leybourne, and Paul Newbold (1997): "Testing the equality of prediction mean squared errors," International Journal of Forecasting, 13, 281-291.

HoDRICK, RoBert (1992): "Dividend yields and expected stock returns: Alternative procedures for inference and measurement," Review of Financial Studies, 5, 357-386.

Horvath, Michael T. K., and Mark W. Watson (1995): "Testing for cointegration when some of the cointegration vectors are prespecified," Econometric Theory, 11, 984-1014.

Inoue, Atsushi, AND Lutz Kilian (2002): "In-sample or out-of-sample tests of predictability: Which one should we use?," mimeo.

Johansen, Søren (1988): "The Statistical Analysis of Cointegration Vectors," Journal of Economic Dynamics and Control, 12(2), 231-254.

(1991): "Estimation and Hypothesis Testing of Cointegration Vectors in Gaussian Vector Autoregressive Models," Econometrica, 59(6), 1551-1580.

Jorion, Philippe, and Frederick Mishkin (1991): "A multicountry comparison of termstructure forecasts at long horizons," Journal of Financial Economics, 29(1), 59-80.

Lamont, Owen (1998): "Earnings and expected returns," Journal of Finance, 53(5), 1563-1587.

- (2001): "Economic tracking portfolios," Journal of Econometrics, 105(1), 161-184.

Lettau, Martin, and Sydney Ludvigson (2001a): "Consumption, aggregate wealth and expected stock returns," Journal of Finance, 56(3), 815-849.

- (2001b): "Measuring and modelling variation in the risk-return trade-off," CEPR Discussion Paper, 3105.

(2001c): "Resurrecting the (C)CAPM: A Cross-Sectional Test When Risk Premia Are Time-Varying," Journal of Political Economy, 109(6), 1238-1287.

(2002a): "Expected returns and expected dividend growth," manuscript, New York University. 
(2002b): "Time-varying risk premia and the cost of capital: An alternative implication of the Q theory of investment," Journal of Monetary Economics, 49(1), 31-66.

Liew, Jimmy, AND Maria Vassalou (2000): "Can book-to-market, size and momentum be risk factors that predict economic growth?," Journal of Financial Economics, 57(2), 221-245.

Lütkepohl, Helmut, Pentti Saikkonen, and Carsten Trenkler (2000): "Maximum eigenvalue versus trace tests for the cointegration rank of a VAR process," manuscript, Humboldt University Berlin.

Mark, Nelson C. (1995): "Exchange Rates and Fundamentals: Evidence on Long-Horizon Predictability," American Economic Review, 85(1), 201-218.

Mark, Nelson C., And Donggyu Sul (2002): "Asymptotic power advantages of long-horizon regressions," mimeo, Ohio State University.

Miller, Merton H., and Franco Modigliani (1961): "Dividend Policy, Growth, and the Valuation of Shares," Journal of Business, 34(4), 411-433.

Newey, Whitney K., And Kenneth D. West (1987): "A Simple, Postitive Semi-definite, Heteroscedasticity and Autocorrelation Consistent Covariance Matrix," Econometrica, 55(3), 703-708.

Plosser, Charles I., and K. Geert Rouwenhorst (1994): "International term structures and real economic growth," Journal of Monetary Economics, 33(1), 133-155.

Rapach, David E., Mark E. Wohar, and Jesper Rangvid (2002): "Macro variables and international stock return predictability," mimeo.

Santos, Tano, and Pietro Veronesi (2001): "Labor income and predictable stock returns," mimeo, GSB, University of Chicago.

Shiller, Robert J. (2000): Irrational Exuberance. Princeton University Press.

Stock, James H. (1987): "Asymptotic Properties of Least Squares Estimators of Cointegration Vectors," Econometrica, 55, 1035-1056.

VAlkanov, Rossen (2002): "Long-horizon regressions: Theoretical results and applications," Journal of Financial Economics, forthcoming. 
Table 1. Summary statistics. 1973:01 - 2001:12

\begin{tabular}{|c|c|c|c|c|c|c|c|c|c|c|c|c|c|}
\hline & & Belgium & Canada & Denm. & France & Germ. & Italy & Japan & Nether & Norway & Sweden & UK & US \\
\hline \multirow[t]{3}{*}{ Real returns: $r_{t}$} & mean & 0.835 & 1.260 & 5.040 & 3.792 & 3.216 & 1.224 & 0.027 & 1.087 & 4.572 & 7.488 & 2.244 & 3.096 \\
\hline & std. & 16.285 & 17.493 & 17.833 & 23.950 & 17.765 & 22.477 & 14.738 & 18.879 & 28.608 & 25.219 & 17.630 & 13.145 \\
\hline & $\rho_{1}$ & 0.235 & 0.064 & 0.070 & -0.039 & 0.080 & 0.257 & 0.327 & 0.191 & -0.009 & -0.020 & 0.343 & 0.290 \\
\hline \multirow[t]{3}{*}{ Output: $\Delta y_{t}$} & mean & 1.117 & 2.448 & 2.508 & 1.380 & 1.356 & 1.560 & 1.800 & 1.524 & 4.128 & 2.100 & 1.069 & 2.376 \\
\hline & std. & 7.550 & 3.932 & 10.767 & 4.448 & 5.932 & 7.999 & 4.881 & 9.641 & 15.492 & 9.813 & 4.843 & 2.702 \\
\hline & $\rho_{1}$ & -0.455 & -0.135 & -0.336 & -0.324 & -0.369 & -0.294 & -0.231 & -0.485 & -0.440 & -0.372 & -0.185 & 0.393 \\
\hline \multirow[t]{2}{*}{ Rel. interest rates: $\mathrm{rrel}_{t}$} & mean & -0.052 & -0.006 & -0.024 & -0.033 & -0.011 & -0.021 & -0.085 & -0.012 & 0.032 & 0.008 & -0.027 & -0.028 \\
\hline & std. & 0.731 & 2.576 & 7.509 & 2.299 & 2.153 & 4.314 & 1.752 & 3.177 & 4.329 & 3.393 & 2.612 & 1.664 \\
\hline \multirow[t]{3}{*}{ Dividend yields: $d y_{t}$} & mean & 1.071 & 0.845 & 0.905 & 1.161 & 1.009 & 0.731 & 0.038 & 1.124 & 0.802 & 0.813 & 1.401 & 0.959 \\
\hline & std. & 0.332 & 0.520 & 0.220 & 0.123 & 0.100 & 0.421 & 0.273 & 0.624 & 0.202 & 0.098 & 0.074 & 0.163 \\
\hline & $\rho_{1}$ & 0.991 & 0.975 & 0.973 & 0.970 & 0.982 & 0.946 & 0.991 & 0.982 & 0.961 & 0.940 & 0.963 & 0.986 \\
\hline \multirow[t]{3}{*}{ Price-earning: $p e_{t}$} & mean & 2.512 & 2.610 & 2.723 & 2.678 & 2.600 & 3.171 & 3.540 & 2.436 & 2.551 & 2.794 & 2.570 & 2.673 \\
\hline & std. & 0.240 & 0.480 & 0.232 & 0.092 & 0.059 & 0.444 & 0.225 & 0.440 & 0.696 & 0.141 & 0.102 & 0.136 \\
\hline & $\rho_{1}$ & 0.938 & 0.975 & 0.948 & 0.948 & 0.959 & 0.888 & 0.987 & 0.939 & 0.961 & 0.878 & 0.971 & 0.981 \\
\hline
\end{tabular}


Table 2. Cointegration between real activity and share prices

\begin{tabular}{|c|c|c|c|c|c|c|c|c|c|c|c|c|c|}
\hline & \multicolumn{6}{|c|}{ Johansen cointegration tests } & \multicolumn{4}{|c|}{ Imposed cointegration vectors } & & & \\
\hline & \multicolumn{2}{|c|}{$\lambda_{\max }$} & \multicolumn{2}{|c|}{$\lambda_{\text {Trace }}$} & \multicolumn{2}{|c|}{ Properties of $\widehat{\beta}^{\prime}$} & \multicolumn{2}{|c|}{$\underline{\text { Univariate PP tests }}$} & \multicolumn{2}{|c|}{ Horvath-Watson } & \multicolumn{3}{|c|}{$\underline{\text { Summary statistics }}$} \\
\hline & $r=0$ & $r \leq 1$ & $r=0$ & $r \leq 1$ & $-(1 / \widehat{\gamma})$ & $\widehat{\beta}^{\prime}=[1,-1]$ & $\widehat{\beta}^{\prime}=[1,-1 / \widehat{\gamma}]$ & $\beta^{\prime}=[1,-1]$ & $\widehat{\beta}^{\prime}=[1,-1 / \widehat{\gamma}]$ & $\beta^{\prime}=[1,-1]$ & mean & std. & $\rho_{1}$ \\
\hline Belgium & 11.28 & 0.00 & 11.28 & 0.00 & -0.26 & 8.29 & -3.59 & -1.69 & 16.69 & 3.94 & 4.53 & 0.09 & 0.94 \\
\hline Canada & 12.77 & 1.47 & 14.24 & 1.47 & -0.64 & 4.16 & -3.88 & -2.95 & 9.04 & 5.52 & 4.48 & 0.11 & 0.93 \\
\hline Denmark & 16.07 & 0.48 & 16.55 & 0.48 & -0.49 & 8.70 & -3.14 & -0.94 & 15.01 & 6.59 & 4.53 & 0.11 & 0.93 \\
\hline France & 12.34 & 0.35 & 12.69 & 0.35 & -0.19 & 10.63 & -3.65 & -0.71 & 12.77 & 1.28 & 4.57 & 0.06 & 0.93 \\
\hline Germany & 14.82 & 0.09 & 14.92 & 0.09 & -0.28 & 10.81 & -3.24 & -1.03 & 15.15 & 3.59 & 4.58 & 0.06 & 0.93 \\
\hline Italy & 14.84 & 0.83 & 15.66 & 0.83 & -0.24 & 10.90 & -3.69 & -1.77 & 11.44 & 3.86 & 4.44 & 0.13 & 0.96 \\
\hline Japan & 10.62 & 0.93 & 11.55 & 0.93 & -0.44 & 6.75 & -2.63 & -1.61 & 8.87 & 3.36 & 4.49 & 0.12 & 0.97 \\
\hline Netherl. & 14.61 & 0.08 & 14.68 & 0.08 & -0.22 & 10.33 & -3.83 & -1.62 & 14.04 & 3.74 & 4.51 & 0.09 & 0.92 \\
\hline Norway & 10.09 & 1.37 & 11.46 & 1.37 & -0.44 & 6.41 & -3.07 & -1.71 & 8.57 & 3.45 & 4.47 & 0.22 & 0.95 \\
\hline Sweden & 14.52 & 0.06 & 14.59 & 0.06 & -0.24 & 10.19 & -3.59 & -0.69 & 14.00 & 4.77 & 4.57 & 0.07 & 0.90 \\
\hline UK & 20.15 & 0.05 & 20.20 & 0.05 & -0.43 & 22.44 & -2.59 & -1.13 & 9.51 & 2.83 & 3.62 & 0.07 & 0.93 \\
\hline USA & 12.68 & 0.15 & 12.83 & 0.15 & -0.36 & 11.83 & -3.69 & -0.85 & 14.71 & 0.62 & 4.54 & 0.09 & 0.97 \\
\hline \multicolumn{14}{|c|}{ Critical values } \\
\hline $90 \%$ & 10.60 & 2.71 & 13.14 & 2.71 & & 2.71 & -2.27 & -2.27 & 7.3 & 7.3 & & & \\
\hline $95 \%$ & 14.04 & 3.96 & 15.20 & 3.96 & & 3.84 & -2.88 & -2.88 & 10.18 & 10.18 & & & \\
\hline
\end{tabular}

Notes: See separate page with notes to tables. 
Table 3. Predicting monthly real returns

\begin{tabular}{|c|c|c|c|c|c|c|c|c|}
\hline & & $\Delta y_{t-1}$ & rrel $_{t-1}$ & $d y_{t-1}$ & $p e_{t-1}$ & $r_{t-1}$ & $\widehat{p y}_{t-1}$ & $\bar{R}^{2}$ \\
\hline & 1 & & & & & & $\underset{(3.33)}{\mathbf{0 . 1 1}}$ & $\begin{array}{l}\mathbf{0 . 0 3} \\
(0.00)\end{array}$ \\
\hline \multirow[t]{3}{*}{ Belgium } & 2 & $-{ }_{(1.43)}^{0.16}$ & $-\begin{array}{r}0.00 \\
(0.88)\end{array}$ & $-\underset{(1.52)}{0.01}$ & $-\underset{(2.45)}{\mathbf{0 . 0 1}}$ & $\begin{array}{l}\mathbf{0 . 2 3} \\
(4.33)\end{array}$ & & $\begin{array}{l}\mathbf{0 . 0 7} \\
(0.00)\end{array}$ \\
\hline & 3 & $\begin{array}{r}-0.20 \\
(1.79)\end{array}$ & $\begin{array}{r}-0.00 \\
(0.90)\end{array}$ & $\begin{array}{r}-0.00 \\
(0.56)\end{array}$ & $\begin{array}{c}0.00 \\
(0.66) \\
\end{array}$ & $\begin{array}{r}\mathbf{0 . 2 4} \\
(4.51)\end{array}$ & $\underset{(2.58)}{\mathbf{0 . 1 0}}$ & $\begin{array}{l}\mathbf{0 . 0 9} \\
(0.00)\end{array}$ \\
\hline & 1 & & & & & & $\begin{array}{l}\mathbf{0 . 0 8} \\
(3.36)\end{array}$ & $\begin{array}{l}\mathbf{0 . 0 3} \\
(0.00)\end{array}$ \\
\hline \multirow[t]{3}{*}{ Canada } & 2 & $\begin{array}{c}0.29 \\
(1.19)\end{array}$ & $-\underset{(1.84)}{\mathbf{0 . 0 0}}$ & $\begin{array}{r}-0.01 \\
(0.76)\end{array}$ & $\begin{array}{r}-0.00 \\
(0.22)\end{array}$ & $\begin{array}{l}0.03 \\
(0.50)\end{array}$ & & $\begin{array}{l}0.01 \\
(0.21)\end{array}$ \\
\hline & 3 & $\begin{array}{l}0.31 \\
(1.30)\end{array}$ & $-\underset{(1.25)}{0.00}$ & $\begin{array}{r}-0.00 \\
(0.46)\end{array}$ & $-\underset{(0.34)}{0.00}$ & $\begin{array}{c}0.06 \\
(1.01)\end{array}$ & $\begin{array}{l}\mathbf{0 . 0 8} \\
(3.06)\end{array}$ & $\begin{array}{l}\mathbf{0 . 0 3} \\
(0.01)\end{array}$ \\
\hline & 1 & & & & & & $\begin{array}{l}0.02 \\
(0.71)\end{array}$ & $\begin{array}{r}-0.00 \\
(0.48)\end{array}$ \\
\hline \multirow[t]{3}{*}{ Denmark } & 2 & $\begin{array}{l}0.07 \\
(0.74)\end{array}$ & $-\underset{(2.93)}{\mathbf{0 . 0 0}}$ & $-\underset{(1.07)}{0.01}$ & $-\underset{(1.56)}{0.02}$ & $\begin{array}{l}0.04 \\
(0.67)\end{array}$ & & $\begin{array}{l}\mathbf{0 . 0 3} \\
(0.02)\end{array}$ \\
\hline & 3 & $\begin{array}{l}0.06 \\
(0.63) \\
\end{array}$ & $\begin{array}{r}-\mathbf{0 . 0 0} \\
(3.01) \\
\end{array}$ & $\begin{array}{r}-0.01 \\
(1.09) \\
\end{array}$ & $-\begin{array}{r}0.01 \\
(1.40)\end{array}$ & $\begin{array}{r}0.05 \\
(0.85) \\
\end{array}$ & $\begin{array}{l}0.03 \\
(0.97) \\
\end{array}$ & $\begin{array}{l}\mathbf{0 . 0 3} \\
(0.03) \\
\end{array}$ \\
\hline & 1 & & & & & & $\underset{(2.26)}{\mathbf{0 . 1 4}}$ & $\begin{array}{l}\mathbf{0 . 0 1} \\
(0.02)\end{array}$ \\
\hline \multirow[t]{3}{*}{ France } & 2 & $-\underset{(0.01)}{0.00}$ & $-\underset{(2.05)}{\mathbf{0 . 0 1}}$ & $\begin{array}{l}0.01 \\
(0.41)\end{array}$ & $\begin{array}{l}0.00 \\
(0.12)\end{array}$ & $-\underset{(1.01)}{0.05}$ & & $-\begin{array}{r}0.00 \\
(0.43)\end{array}$ \\
\hline & 3 & $\begin{array}{r}-0.17 \\
(0.58) \\
\end{array}$ & $\begin{array}{r}-\mathbf{0 . 0 1} \\
(2.40) \\
\end{array}$ & $\begin{array}{l}0.01 \\
(0.57) \\
\end{array}$ & $\begin{array}{l}\mathbf{0 . 0 4}(.04) \\
(1.89)\end{array}$ & $\begin{array}{r}-0.04 \\
(0.65) \\
\end{array}$ & $\begin{array}{l}\mathbf{0 . 2 8} \\
(3.15) \\
\end{array}$ & $\begin{array}{r}\mathbf{0 . 0 3} \\
(0.02) \\
\end{array}$ \\
\hline & 1 & & & & & & $\begin{array}{l}0.03 \\
(0.76)\end{array}$ & $\begin{array}{r}-0.00 \\
(0.45)\end{array}$ \\
\hline \multirow[t]{3}{*}{ Germany } & 2 & $\begin{array}{l}0.17 \\
(1.06)\end{array}$ & $-\underset{(2.39)}{\mathbf{0 . 0 0}}$ & $-\underset{(1.92)}{\mathbf{0 . 0 3}}$ & $\begin{array}{r}-\mathbf{0 . 0 5} \\
(2.20)\end{array}$ & $\begin{array}{l}0.05 \\
(0.95)\end{array}$ & & $\begin{array}{l}\mathbf{0 . 0 2} \\
(0.02)\end{array}$ \\
\hline & 3 & $\begin{array}{l}0.15 \\
(0.96) \\
\end{array}$ & $\begin{array}{r}-\mathbf{0 . 0 0} \\
(2.54) \\
\end{array}$ & $\begin{array}{r}-\mathbf{0 . 0 3} \\
(1.88) \\
\end{array}$ & $\begin{array}{r}-\mathbf{0 . 0 4} \\
(1.95) \\
\end{array}$ & $\begin{array}{l}0.06 \\
(1.14) \\
\end{array}$ & $\begin{array}{l}0.05 \\
(1.04) \\
\end{array}$ & $\begin{array}{l}\mathbf{0 . 0 2} \\
(0.03) \\
\end{array}$ \\
\hline & 1 & & & & & & $\underset{(2.18)}{\mathbf{0 . 0 6}}$ & $\begin{array}{l}\mathbf{0 . 0 1} \\
(0.03)\end{array}$ \\
\hline \multirow[t]{2}{*}{ Italy } & 2 & $-\underset{(0.38)}{0.11}$ & $\begin{array}{l}0.00 \\
(0.31)\end{array}$ & $\begin{array}{l}0.00 \\
(0.39)\end{array}$ & $-\underset{(1.73)}{\mathbf{0 . 0 1}}$ & $\begin{array}{l}\mathbf{0 . 2 3} \\
(3.22)\end{array}$ & & $\begin{array}{l}\mathbf{0 . 0 4} \\
(0.02)\end{array}$ \\
\hline & 3 & $\begin{array}{r}-0.12 \\
(0.43)\end{array}$ & $\begin{array}{l}0.00 \\
(0.18)\end{array}$ & $\begin{array}{l}0.00 \\
(0.57)\end{array}$ & $-\underset{(1.44)}{0.01}$ & $\begin{array}{l}\mathbf{0 . 2 4} \\
(3.30)\end{array}$ & $\begin{array}{c}0.06^{a} \\
(0.89)\end{array}$ & $\begin{array}{c}\mathbf{0 . 0 4} \\
(0.03)\end{array}$ \\
\hline
\end{tabular}


Table 3. Continued

\begin{tabular}{|c|c|c|c|c|c|c|c|c|}
\hline & & $\Delta y_{t-1}$ & rrel $_{t-1}$ & $d y_{t-1}$ & $p e_{t-1}$ & $r_{t-1}$ & $\widehat{p y}_{t-1}$ & $\bar{R}^{2}$ \\
\hline & 1 & & & & & & $\begin{array}{l}0.01 \\
(0.55)\end{array}$ & $-\underset{(0.58)}{0.00}$ \\
\hline \multirow[t]{3}{*}{ Japan } & 2 & $-\underset{(1.75)}{\mathbf{0 . 2 7}}$ & $\underset{(2.15)}{-\mathbf{0 . 0 0}}$ & $\begin{array}{l}0.01 \\
(0.92)\end{array}$ & $\begin{array}{l}\mathbf{0 . 0 1} \\
(0.60)\end{array}$ & $\begin{array}{l}\mathbf{0 . 3 2} \\
(6.19)\end{array}$ & & $\begin{array}{l}\mathbf{0 . 1 2} \\
(0.00)\end{array}$ \\
\hline & 3 & $\begin{array}{r}-\mathbf{0 . 2 6} \\
(1.68) \\
\end{array}$ & $\begin{array}{r}-\mathbf{0 . 0 0} \\
(1.98) \\
\end{array}$ & $\begin{array}{c}0.02 \\
(1.27) \\
\end{array}$ & $\begin{array}{c}0.01 \\
(0.93) \\
\end{array}$ & $\begin{array}{r}\mathbf{0 . 3 3} \\
(6.31) \\
\end{array}$ & $\begin{array}{r}0.02 \\
(1.38) \\
\end{array}$ & $\begin{array}{l}\mathbf{0 . 1 2} \\
(0.00) \\
\end{array}$ \\
\hline & 1 & & & & & & $\begin{array}{l}\mathbf{0 . 0 9} \\
(2.79)\end{array}$ & $\begin{array}{l}\mathbf{0 . 0 2} \\
(0.01)\end{array}$ \\
\hline \multirow[t]{3}{*}{ Netherl. } & 2 & $\begin{array}{r}-0.05 \\
(0.46)\end{array}$ & $\begin{array}{r}-0.00 \\
(1.27)\end{array}$ & $\begin{array}{l}0.00 \\
(0.24)\end{array}$ & $\begin{array}{l}0.00 \\
(0.79)\end{array}$ & $\underset{(2.64)}{\mathbf{0 . 1 5}}$ & & $\begin{array}{l}\mathbf{0 . 0 2} \\
(0.01)\end{array}$ \\
\hline & 3 & $\begin{array}{r}-0.13 \\
(1.15) \\
\end{array}$ & $\begin{array}{r}-0.00 \\
(1.28) \\
\end{array}$ & $\begin{array}{r}0.00 \\
(0.83) \\
\end{array}$ & $\begin{array}{l}\mathbf{0 . 0 0} \\
(1.77)\end{array}$ & $\begin{array}{l}\mathbf{0 . 1 7} \\
(2.99) \\
\end{array}$ & $\begin{array}{l}\mathbf{0 . 1 7} \\
(3.02) \\
\end{array}$ & $\begin{array}{l}\mathbf{0 . 0 5} \\
(0.01) \\
\end{array}$ \\
\hline & 1 & & & & & & $\underset{(2.65)}{\mathbf{0 . 0 5}}$ & $\begin{array}{l}\mathbf{0 . 0 2} \\
(0.01)\end{array}$ \\
\hline \multirow[t]{3}{*}{ Norway } & 2 & $\begin{array}{l}0.06 \\
(0.57)\end{array}$ & $-\underset{(1.43)}{0.00}$ & $\begin{array}{c}0.02 \\
(1.18)\end{array}$ & $\begin{array}{r}-0.00 \\
(0.21)\end{array}$ & $-\begin{array}{r}0.04 \\
(0.62)\end{array}$ & & $-\underset{(0.56)}{0.00}$ \\
\hline & 3 & $\begin{array}{r}-0.13 \\
(1.20) \\
\end{array}$ & $\begin{array}{r}-0.00 \\
(1.41) \\
\end{array}$ & $\begin{array}{l}\mathbf{0 . 0 3} \\
(1.71) \\
\end{array}$ & $\begin{array}{l}\mathbf{0 . 0 2} \\
(2.44) \\
\end{array}$ & $\begin{array}{l}0.03 \\
(0.55) \\
\end{array}$ & $\begin{array}{l}\mathbf{0 . 3 7} \\
(4.64) \\
\end{array}$ & $\begin{array}{r}\mathbf{0 . 0 7} \\
(0.00) \\
\end{array}$ \\
\hline & 1 & & & & & & $\begin{array}{l}0.02 \\
(0.34)\end{array}$ & $-\underset{(0.73)}{0.00}$ \\
\hline \multirow[t]{3}{*}{ Sweden } & 2 & $-\begin{array}{r}0.12 \\
(0.60)\end{array}$ & $-\underset{(1.13)}{0.00}$ & $\begin{array}{l}0.00 \\
(0.27)\end{array}$ & $-\underset{(1.92)}{\mathbf{0 . 0 2}}$ & $\underset{(2.23)}{\mathbf{0 . 1 5}}$ & & $\begin{array}{l}\mathbf{0 . 0 3} \\
(0.03)\end{array}$ \\
\hline & 3 & $\begin{array}{r}-0.21 \\
(1.08) \\
\end{array}$ & $\begin{array}{r}-0.00 \\
(1.63) \\
\end{array}$ & $\begin{array}{r}-0.01 \\
(0.76) \\
\end{array}$ & $\begin{array}{r}-\mathbf{0 . 0 2} \\
(2.02) \\
\end{array}$ & $\begin{array}{l}\mathbf{0 . 1 8} \\
(2.69) \\
\end{array}$ & $\underset{(2.26)}{\mathbf{0 . 2 1 ^ { a }}}$ & $\begin{array}{r}\mathbf{0 . 0 5} \\
(0.01) \\
\end{array}$ \\
\hline & 1 & & & & & & $\begin{array}{l}0.03 \\
(1.26)\end{array}$ & $\begin{array}{l}0.00 \\
(0.21)\end{array}$ \\
\hline \multirow[t]{3}{*}{ UK } & 2 & $\begin{array}{l}0.12 \\
(0.63)\end{array}$ & $-\underset{(0.37)}{0.00}$ & $\begin{array}{c}0.04 \\
(1.50)\end{array}$ & $\begin{array}{l}0.02 \\
(0.84)\end{array}$ & $\begin{array}{l}\mathbf{0 . 3 5} \\
(6.41)\end{array}$ & & $\begin{array}{l}\mathbf{0 . 1 2} \\
(0.00)\end{array}$ \\
\hline & 3 & $\begin{array}{r}0.10 \\
(0.53) \\
\end{array}$ & $\begin{array}{r}-0.00 \\
(0.44) \\
\end{array}$ & $\begin{array}{c}0.04 \\
(1.42) \\
\end{array}$ & $\begin{array}{l}0.03 \\
(1.22) \\
\end{array}$ & $\begin{array}{r}\mathbf{0 . 3 6} \\
(6.52) \\
\end{array}$ & $\begin{array}{r}0.05 \\
(1.64) \\
\end{array}$ & $\begin{array}{l}\mathbf{0 . 1 2} \\
(0.00)\end{array}$ \\
\hline & 1 & & & & & & $\underset{(2.81)}{\mathbf{0 . 0 6}}$ & $\begin{array}{l}\mathbf{0 . 0 2} \\
(0.01)\end{array}$ \\
\hline \multirow[t]{2}{*}{ US } & 2 & $-\underset{(0.27)}{0.07}$ & $-\underset{(3.01)}{\mathbf{0 . 0 0}}$ & $-\underset{(0.58)}{0.01}$ & $\begin{array}{r}-0.02 \\
(0.85)\end{array}$ & $\begin{array}{l}\mathbf{0 . 2 5} \\
(4.72)\end{array}$ & & $\begin{array}{l}\mathbf{0 . 1 0} \\
(0.00)\end{array}$ \\
\hline & 3 & $\begin{array}{r}-0.10 \\
(0.37)\end{array}$ & $-\underset{(2.99)}{\mathbf{0 . 0 0}}$ & $\begin{array}{l}0.01 \\
(0.36)\end{array}$ & $\begin{array}{l}0.00 \\
(0.21)\end{array}$ & $\begin{array}{l}\mathbf{0 . 2 5} \\
(4.72)\end{array}$ & $\begin{array}{l}\mathbf{0 . 0 6} \\
(2.69)\end{array}$ & $\begin{array}{c}\mathbf{0 . 1 2} \\
(0.00)\end{array}$ \\
\hline
\end{tabular}

Notes: See separate page with notes to tables. 
Table 4. Predicting monthly changes in real activity

\begin{tabular}{|c|c|c|c|c|c|c|c|c|}
\hline & & $\Delta y_{t-1}$ & rrel $_{t-1}$ & $d y_{t-1}$ & $p e_{t-1}$ & $r_{t-1}$ & $\widehat{p y}_{t-1}$ & $\bar{R}^{2}$ \\
\hline & 1 & & & & & & $-\underset{(3.06)}{\mathbf{0 . 0 5}}$ & $\begin{array}{l}\mathbf{0 . 0 2} \\
(0.00)\end{array}$ \\
\hline \multirow[t]{3}{*}{ Belgium } & 2 & $-\underset{(9.40)}{\mathbf{0 . 4 5}}$ & $\begin{array}{r}-0.00 \\
(0.38)\end{array}$ & $-\begin{array}{r}0.00 \\
(0.35)\end{array}$ & $\begin{array}{l}0.00 \\
(0.17)\end{array}$ & $-\begin{array}{r}0.01 \\
(0.30)\end{array}$ & & $\begin{array}{l}\mathbf{0 . 2 0} \\
(0.00)\end{array}$ \\
\hline & 3 & $\begin{array}{r}-\mathbf{0 . 4 4} \\
(9.01) \\
\end{array}$ & $\begin{array}{r}-0.00 \\
(0.37) \\
\end{array}$ & $\begin{array}{r}-0.00 \\
(1.23) \\
\end{array}$ & $\begin{array}{r}-0.00 \\
(1.29) \\
\end{array}$ & $\begin{array}{r}-0.01 \\
(0.45) \\
\end{array}$ & $\begin{array}{r}-\mathbf{0 . 0 4} \\
(2.63) \\
\end{array}$ & $\begin{array}{l}\mathbf{0 . 2 1} \\
(0.00) \\
\end{array}$ \\
\hline & 1 & & & & & & $-\underset{(1.93)}{\mathbf{0 . 0 1}}$ & $\begin{array}{l}\mathbf{0 . 0 1} \\
(0.05)\end{array}$ \\
\hline \multirow[t]{3}{*}{ Canada } & 2 & $\begin{array}{r}-\mathbf{0 . 1 7} \\
(3.15)\end{array}$ & $\begin{array}{r}-0.00 \\
(0.05)\end{array}$ & $\begin{array}{c}0.00 \\
(1.05)\end{array}$ & $\underset{(2.74)}{\mathbf{0 . 0 0}}$ & $\begin{array}{l}\mathbf{0 . 0 2} \\
(2.13)\end{array}$ & & $\begin{array}{l}\mathbf{0 . 0 6} \\
(0.00)\end{array}$ \\
\hline & 3 & $\begin{array}{r}-\mathbf{0 . 1 7} \\
(3.24)\end{array}$ & $\begin{array}{r}-0.00 \\
(0.45)\end{array}$ & $\begin{array}{c}0.00 \\
(0.82)\end{array}$ & $\underset{(2.84)}{\mathbf{0 . 0 0}}$ & $\begin{array}{l}\mathbf{0 . 0 2} \\
(1.77)\end{array}$ & $-\underset{(2.20)}{\mathbf{0 . 0 1}}$ & $\begin{array}{l}\mathbf{0 . 0 7} \\
(0.00)\end{array}$ \\
\hline & 1 & & & & & & $-\underset{(3.58)}{\mathbf{0 . 0 6}}$ & $\begin{array}{c}\mathbf{0 . 0 4} \\
(0.00)\end{array}$ \\
\hline \multirow[t]{3}{*}{ Denmark } & 2 & $-\underset{(6.64)}{\mathbf{0 . 3 5}}$ & $-\underset{(1.82)}{\mathbf{0 . 0 0}}$ & $-\underset{(1.30)}{0.01}$ & $-\begin{array}{r}0.01 \\
(0.91)\end{array}$ & $\begin{array}{l}0.00 \\
(0.10)\end{array}$ & & $\begin{array}{c}\mathbf{0 . 1 2} \\
(0.02)\end{array}$ \\
\hline & 3 & $-\begin{array}{r}\mathbf{0 . 3 4} \\
(6.36) \\
\end{array}$ & $\begin{array}{r}-0.00 \\
(1.51) \\
\end{array}$ & $\begin{array}{r}-0.01 \\
(1.26) \\
\end{array}$ & $\begin{array}{r}-0.01 \\
(1.36) \\
\end{array}$ & $\begin{array}{r}-0.02 \\
(0.49) \\
\end{array}$ & $\begin{array}{r}\mathbf{0 . 0 5} \\
(3.03) \\
\end{array}$ & $\begin{array}{r}\mathbf{0 . 1 4} \\
(0.00) \\
\end{array}$ \\
\hline & 1 & & & & & & $-\underset{(2.83)}{\mathbf{0 . 0 3}}$ & $\begin{array}{l}\mathbf{0 . 0 2} \\
(0.00)\end{array}$ \\
\hline \multirow[t]{3}{*}{ France } & 2 & $-\underset{(6.58)}{\mathbf{0 . 3 4}}$ & $\begin{array}{l}0.00 \\
(0.25)\end{array}$ & $\begin{array}{l}0.00 \\
(0.27)\end{array}$ & $\begin{array}{c}0.01 \\
(1.60)\end{array}$ & $\begin{array}{l}0.01 \\
(0.73)\end{array}$ & & $\begin{array}{c}\mathbf{0 . 1 0} \\
(0.00)\end{array}$ \\
\hline & 3 & $\begin{array}{r}-\mathbf{0 . 3 2} \\
(6.23) \\
\end{array}$ & $\begin{array}{r}0.00 \\
(0.40) \\
\end{array}$ & $\begin{array}{r}0.00 \\
(0.20) \\
\end{array}$ & $\begin{array}{r}0.00 \\
(0.51) \\
\end{array}$ & $\begin{array}{l}0.01 \\
(0.56) \\
\end{array}$ & $\begin{array}{r}-0.03 \\
(1.43) \\
\end{array}$ & $\begin{array}{r}\mathbf{0 . 1 1} \\
(0.02) \\
\end{array}$ \\
\hline & 1 & & & & & & $-\underset{(3.95)}{\mathbf{0 . 0 6}}$ & $\begin{array}{c}\mathbf{0 . 0 4} \\
(0.00)\end{array}$ \\
\hline \multirow[t]{3}{*}{ Germany } & 2 & $\begin{array}{r}-\mathbf{0 . 3 8} \\
(7.48)\end{array}$ & $\begin{array}{c}0.00 \\
(0.61)\end{array}$ & $\begin{array}{r}-0.01 \\
(1.05)\end{array}$ & $\begin{array}{r}-0.00 \\
(0.17)\end{array}$ & $\begin{array}{l}0.00 \\
(0.22)\end{array}$ & & $\begin{array}{l}\mathbf{0 . 1 3} \\
(0.02)\end{array}$ \\
\hline & 3 & $\begin{array}{r}-\mathbf{0 . 3 6} \\
(7.28) \\
\end{array}$ & $\begin{array}{r}-0.00 \\
(1.26) \\
\end{array}$ & $\begin{array}{r}-0.01 \\
(1.20)\end{array}$ & $\begin{array}{r}-0.01 \\
(0.91) \\
\end{array}$ & $\begin{array}{r}-0.01 \\
(0.52) \\
\end{array}$ & $\begin{array}{r}\mathbf{0 . 0 6} \\
(3.80) \\
\end{array}$ & $\begin{array}{r}\mathbf{0 . 1 7} \\
(0.03) \\
\end{array}$ \\
\hline & 1 & & & & & & $-\underset{(2.74)}{\mathbf{0 . 0 2}}$ & $\begin{array}{c}\mathbf{0 . 0 2} \\
(0.01)\end{array}$ \\
\hline \multirow[t]{2}{*}{ Italy } & 2 & $-\underset{(5.95)}{\mathbf{0 . 4 0}}$ & $\begin{array}{c}0.00 \\
(0.09)\end{array}$ & $\begin{array}{r}-0.00 \\
(0.78)\end{array}$ & $\begin{array}{c}0.00 \\
(1.00)\end{array}$ & $\begin{array}{l}0.00 \\
(0.12)\end{array}$ & & $\begin{array}{c}\mathbf{0 . 1 4} \\
(0.00)\end{array}$ \\
\hline & 3 & $-\underset{(5.89)}{\mathbf{0 . 4 0}}$ & $\begin{array}{c}0.00 \\
(0.34)\end{array}$ & $\begin{array}{r}-0.00 \\
(1.14)\end{array}$ & $\begin{array}{l}0.00 \\
(0.51)\end{array}$ & $\begin{array}{r}-0.00 \\
(0.10)\end{array}$ & $-\mathbf{( 1 . 7 7 )}^{\mathbf{0 . 0 2}}$ & $\begin{array}{l}\mathbf{0 . 0 4} \\
(0.03)\end{array}$ \\
\hline
\end{tabular}


Table 4. Continued

\begin{tabular}{|c|c|c|c|c|c|c|c|c|}
\hline & & $\Delta y_{t-1}$ & rrel $_{t-1}$ & $d y_{t-1}$ & $p e_{t-1}$ & $r_{t-1}$ & $\widehat{p y}_{t-1}$ & $\bar{R}^{2}$ \\
\hline \multirow{4}{*}{ Japan } & 1 & & & & & & $\begin{array}{r}-\mathbf{0 . 0 2} \\
(3.32)\end{array}$ & $\begin{array}{l}\mathbf{0 . 0 2} \\
(0.00)\end{array}$ \\
\hline & 2 & $\begin{array}{r}-\mathbf{0 . 2 7} \\
(5.12)\end{array}$ & $\begin{array}{r}-\mathbf{0 . 0 0} \\
(1.69)\end{array}$ & $\begin{array}{l}\mathbf{0 . 0 1} \\
(2.98)\end{array}$ & $\begin{array}{l}\mathbf{0 . 0 1} \\
(3.29)\end{array}$ & $\begin{array}{l}0.02 \\
(1.32)\end{array}$ & & $\begin{array}{l}\mathbf{0 . 0 9} \\
(0.00)\end{array}$ \\
\hline & 3 & $\begin{array}{r}-\mathbf{0 . 2 8} \\
(5.39) \\
\end{array}$ & $\begin{array}{r}-\mathbf{0 . 0 0} \\
(2.08) \\
\end{array}$ & $\begin{array}{r}\mathbf{0 . 0 1} \\
(1.98) \\
\end{array}$ & $\begin{array}{l}\mathbf{0 . 0 1} \\
(2.42) \\
\end{array}$ & $\begin{array}{l}0.02 \\
(0.95) \\
\end{array}$ & $\begin{array}{r}-\mathbf{0 . 0 2} \\
(3.29) \\
\end{array}$ & $\begin{array}{l}\mathbf{0 . 1 2} \\
(0.00) \\
\end{array}$ \\
\hline & 1 & & & & & & $\begin{array}{r}\mathbf{0 . 0 6} \\
(3.57)\end{array}$ & $\begin{array}{l}\mathbf{0 . 0 3} \\
(0.00)\end{array}$ \\
\hline \multirow[t]{3}{*}{ Netherl. } & 2 & $\begin{array}{r}\mathbf{0 . 4 9} \\
(9.78)\end{array}$ & $\begin{array}{r}-0.00 \\
(0.08)\end{array}$ & $\begin{array}{r}-0.00 \\
(0.28)\end{array}$ & $\begin{array}{l}0.00 \\
(0.14)\end{array}$ & $\begin{array}{l}0.03 \\
(1.00)\end{array}$ & & $\begin{array}{l}\mathbf{0 . 2 4} \\
(0.01)\end{array}$ \\
\hline & 3 & $\begin{array}{r}-0.45 \\
(8.83) \\
\end{array}$ & $\begin{array}{r}-0.00 \\
(0.09) \\
\end{array}$ & $\begin{array}{r}-0.00 \\
(1.04) \\
\end{array}$ & $\begin{array}{r}-0.00 \\
(1.16) \\
\end{array}$ & $\begin{array}{c}0.02 \\
(0.60) \\
\end{array}$ & $\begin{array}{r}-\mathbf{0 . 1 0} \\
(3.83) \\
\end{array}$ & $\begin{array}{l}\mathbf{0 . 2 7} \\
(0.01) \\
\end{array}$ \\
\hline & 1 & & & & & & $\begin{array}{r}-\mathbf{0 . 0 2} \\
(2.11)\end{array}$ & $\begin{array}{l}\mathbf{0 . 0 1} \\
(0.04)\end{array}$ \\
\hline \multirow[t]{3}{*}{ Norway } & 2 & $\begin{array}{r}-\mathbf{0 . 4 6} \\
(8.23)\end{array}$ & $\begin{array}{r}-0.00 \\
(0.58)\end{array}$ & $\begin{array}{l}0.00 \\
(0.16)\end{array}$ & $\begin{array}{l}0.00 \\
(0.13)\end{array}$ & $\begin{array}{l}0.02 \\
(0.63)\end{array}$ & & $\begin{array}{l}\mathbf{0 . 2 0} \\
(0.00)\end{array}$ \\
\hline & 3 & $\begin{array}{r}\mathbf{0 . 3 9 9} \\
(6.59) \\
\end{array}$ & $\begin{array}{r}-0.00 \\
(0.65) \\
\end{array}$ & $\begin{array}{r}-0.03 \\
(0.13) \\
\end{array}$ & $\begin{array}{r}-0.01 \\
(1.64) \\
\end{array}$ & $\begin{array}{r}-0.01 \\
(0.18) \\
\end{array}$ & $\begin{array}{r}\mathbf{0 . 1 3} \\
(3.12) \\
\end{array}$ & $\begin{array}{r}\mathbf{0 . 2 3} \\
(0.00) \\
\end{array}$ \\
\hline & 1 & & & & & & $\begin{array}{r}-\mathbf{0 . 1 0} \\
(4.65)\end{array}$ & $\begin{array}{l}\mathbf{0 . 0 6} \\
(0.00)\end{array}$ \\
\hline \multirow[t]{3}{*}{ Sweden } & 2 & $\begin{array}{r}-\mathbf{0 . 3 5} \\
(5.72)\end{array}$ & $\begin{array}{r}-0.00 \\
(1.01)\end{array}$ & $-\underset{(1.61)}{0.01}$ & $\begin{array}{l}\mathbf{0 . 0 1} \\
(1.92)\end{array}$ & $\begin{array}{r}-0.03 \\
(1.38)\end{array}$ & & $\begin{array}{l}\mathbf{0 . 1 3} \\
(0.00)\end{array}$ \\
\hline & 3 & $\begin{array}{r}-\mathbf{0 . 3 1} \\
(5.01) \\
\end{array}$ & $\begin{array}{r}-0.00 \\
(0.22) \\
\end{array}$ & $\begin{array}{l}0.00 \\
(0.02) \\
\end{array}$ & $\begin{array}{l}\mathbf{0 . 0 1} \\
(2.09) \\
\end{array}$ & $\begin{array}{r}-\mathbf{0 . 0 4} \\
(2.12) \\
\end{array}$ & $\begin{array}{c}-\mathbf{0 . 0 9}^{a} \\
(3.37) \\
\end{array}$ & $\begin{array}{l}\mathbf{0 . 1 7} \\
(0.00) \\
\end{array}$ \\
\hline & 1 & & & & & & $\begin{array}{r}-\mathbf{0 . 0 2} \\
(2.12)\end{array}$ & $\begin{array}{l}\mathbf{0 . 0 1} \\
(0.04)\end{array}$ \\
\hline \multirow[t]{3}{*}{ UK } & 2 & $-\underset{(3.61)}{\mathbf{0 . 2 0}}$ & $\begin{array}{l}0.00 \\
(0.29)\end{array}$ & $\begin{array}{r}-0.01 \\
(0.97)\end{array}$ & $\begin{array}{r}-0.00 \\
(0.27)\end{array}$ & $\begin{array}{r}-0.01 \\
(0.44)\end{array}$ & & $\begin{array}{l}\mathbf{0 . 0 3} \\
(0.01)\end{array}$ \\
\hline & 3 & $\begin{array}{r}-\mathbf{0 . 2 0} \\
(3.52) \\
\end{array}$ & $\begin{array}{l}0.00 \\
(0.35) \\
\end{array}$ & $\begin{array}{r}-0.01 \\
(0.88) \\
\end{array}$ & $\begin{array}{r}-0.00 \\
(0.64) \\
\end{array}$ & $\begin{array}{r}-0.01 \\
(0.54) \\
\end{array}$ & $\begin{array}{r}-0.05 \\
(1.56) \\
\end{array}$ & $\begin{array}{r}\mathbf{0 . 0 4} \\
(0.01) \\
\end{array}$ \\
\hline & 1 & & & & & & $\begin{array}{r}-\mathbf{0 . 0 1} \\
(2.58)\end{array}$ & $\begin{array}{l}\mathbf{0 . 0 2} \\
(0.01)\end{array}$ \\
\hline \multirow[t]{2}{*}{ US } & 2 & $\begin{array}{l}\mathbf{0 . 3 6} \\
(6.90)\end{array}$ & $\begin{array}{l}0.00 \\
(0.54)\end{array}$ & $\begin{array}{l}\mathbf{0 . 0 1} \\
(2.12)\end{array}$ & $\begin{array}{l}\mathbf{0 . 0 1} \\
(2.53)\end{array}$ & $\begin{array}{l}0.01 \\
(1.42)\end{array}$ & & $\begin{array}{l}\mathbf{0 . 1 7} \\
(0.00)\end{array}$ \\
\hline & 3 & $\begin{array}{l}\mathbf{0 . 3 6} \\
(6.94) \\
\end{array}$ & $\begin{array}{l}0.00 \\
(0.52) \\
\end{array}$ & $\begin{array}{c}0.01 \\
(1.60) \\
\end{array}$ & $\begin{array}{l}\mathbf{0 . 0 1} \\
(1.92)\end{array}$ & $\begin{array}{l}0.02 \\
(1.44) \\
\end{array}$ & $\begin{array}{r}-0.01 \\
(1.16) \\
\end{array}$ & $\begin{array}{l}\mathbf{0 . 1 7} \\
(0.00) \\
\end{array}$ \\
\hline
\end{tabular}

Notes: See separate page with notes to tables. 
Table 5. Predicting long-horizon real returns and changes in real activity

\begin{tabular}{|c|c|c|c|c|c|c|c|}
\hline & & \multicolumn{3}{|c|}{ Real returns } & \multicolumn{3}{|c|}{ Changes in real activity } \\
\hline & & $3 \mathrm{mth}$ & $12 \mathrm{mth}$ & $24 \mathrm{mth}$ & $3 \mathrm{mth}$ & $12 \mathrm{mth}$ & $24 \mathrm{mth}$ \\
\hline & 1. Only $\widehat{p y}$ & $\begin{array}{l}\mathbf{0 . 0 9} \\
(0.00)\end{array}$ & $\begin{array}{l}\mathbf{0 . 2 8} \\
(0.00)\end{array}$ & $\begin{array}{l}\mathbf{0 . 3 4} \\
(0.00)\end{array}$ & $\begin{array}{l}0.00 \\
(0.24)\end{array}$ & $\begin{array}{l}0.01 \\
(0.53)\end{array}$ & $\begin{array}{l}0.00 \\
(0.79)\end{array}$ \\
\hline \multirow[t]{3}{*}{ Belgium } & 2. Only controls & $\begin{array}{l}\mathbf{0 . 0 6} \\
(0.01)\end{array}$ & $\begin{array}{l}\mathbf{0 . 2 5} \\
(0.03)\end{array}$ & $\begin{array}{l}\mathbf{0 . 2 1} \\
(0.00)\end{array}$ & $\begin{array}{c}0.01 \\
(0.24)\end{array}$ & $\begin{array}{l}\mathbf{0 . 2 4} \\
(0.00)\end{array}$ & $\begin{array}{l}\mathbf{0 . 2 5} \\
(0.00)\end{array}$ \\
\hline & 3. Full model & $\begin{array}{l}\mathbf{0 . 1 0} \\
(0.00)\end{array}$ & $\begin{array}{l}\mathbf{0 . 4 2} \\
(0.00)\end{array}$ & $\begin{array}{l}\mathbf{0 . 4 8} \\
(0.00)\end{array}$ & $\begin{array}{l}\mathbf{0 . 0 2} \\
(0.08)\end{array}$ & $\begin{array}{l}\mathbf{0 . 3 4} \\
(0.00)\end{array}$ & $\begin{array}{l}\mathbf{0 . 3 2} \\
(0.00)\end{array}$ \\
\hline & 1. Only $\widehat{p y}$ & $\begin{array}{l}\mathbf{0 . 0 9} \\
(0.00)\end{array}$ & $\begin{array}{l}\mathbf{0 . 3 9} \\
(0.00)\end{array}$ & $\begin{array}{l}\mathbf{0 . 4 6} \\
(0.00)\end{array}$ & $\begin{array}{c}0.00 \\
(0.46)\end{array}$ & $\begin{array}{c}0.01 \\
(0.43)\end{array}$ & $\begin{array}{l}\mathbf{0 . 0 9} \\
(0.09)\end{array}$ \\
\hline \multirow[t]{3}{*}{ Canada } & 2. Only controls & $\begin{array}{c}0.01 \\
(0.51)\end{array}$ & $\begin{array}{l}\mathbf{0 . 1 0} \\
(0.00)\end{array}$ & $\begin{array}{l}\mathbf{0 . 1 2} \\
(0.00)\end{array}$ & $\begin{array}{l}\mathbf{0 . 1 6} \\
(0.00)\end{array}$ & $\begin{array}{l}\mathbf{0 . 3 5} \\
(0.00)\end{array}$ & $\begin{array}{l}\mathbf{0 . 3 8} \\
(0.00)\end{array}$ \\
\hline & 3. Full model & $\begin{array}{l}\mathbf{0 . 0 8} \\
(0.01)\end{array}$ & $\begin{array}{l}\mathbf{0 . 4 5} \\
(0.00)\end{array}$ & $\begin{array}{l}\mathbf{0 . 4 8} \\
(0.00)\end{array}$ & $\begin{array}{l}\mathbf{0 . 1 7} \\
(0.00)\end{array}$ & $\begin{array}{l}\mathbf{0 . 3 4} \\
(0.00)\end{array}$ & $\begin{array}{l}\mathbf{0 . 4 1} \\
(0.00)\end{array}$ \\
\hline & 1. Only $\widehat{p y}$ & $\begin{array}{c}0.01 \\
(0.24)\end{array}$ & $\begin{array}{l}\mathbf{0 . 1 5} \\
(0.00)\end{array}$ & $\begin{array}{l}\mathbf{0 . 3 1} \\
(0.00)\end{array}$ & $\begin{array}{l}\mathbf{0 . 0 3} \\
(0.00)\end{array}$ & $\begin{array}{l}\mathbf{0 . 0 4} \\
(0.03)\end{array}$ & $\begin{array}{c}\mathbf{0 . 1 0} \\
(0.00)\end{array}$ \\
\hline \multirow[t]{3}{*}{ Denmark } & 2. Only controls & $\begin{array}{c}\mathbf{0 . 0 6} \\
(0.01)\end{array}$ & $\begin{array}{c}0.04 \\
(0.12)\end{array}$ & $\begin{array}{l}\mathbf{0 . 1 0} \\
(0.05)\end{array}$ & $\begin{array}{l}\mathbf{0 . 0 7} \\
(0.00)\end{array}$ & $\begin{array}{l}\mathbf{0 . 2 0} \\
(0.00)\end{array}$ & $\begin{array}{c}\mathbf{0 . 1 2} \\
(0.00)\end{array}$ \\
\hline & 3. Full model & $\begin{array}{l}\mathbf{0 . 0 8} \\
(0.00)\end{array}$ & $\begin{array}{l}\mathbf{0 . 1 8} \\
(0.00)\end{array}$ & $\begin{array}{l}\mathbf{0 . 4 0} \\
(0.00)\end{array}$ & $\begin{array}{l}\mathbf{0 . 0 8} \\
(0.00)\end{array}$ & $\begin{array}{l}\mathbf{0 . 2 1} \\
(0.00)\end{array}$ & $\begin{array}{l}\mathbf{0 . 2 1} \\
(0.00)\end{array}$ \\
\hline & 1. Only $\widehat{p y}$ & $\begin{array}{l}\mathbf{0 . 0 5} \\
(0.00)\end{array}$ & $\begin{array}{l}\mathbf{0 . 2 5} \\
(0.00)\end{array}$ & $\begin{array}{l}\mathbf{0 . 3 4} \\
(0.00)\end{array}$ & $\begin{array}{l}\mathbf{0 . 0 4} \\
(0.01)\end{array}$ & $\begin{array}{c}0.07 \\
(0.13)\end{array}$ & $\begin{array}{c}0.00 \\
(0.76)\end{array}$ \\
\hline \multirow[t]{3}{*}{ France } & 2. Only controls & $\begin{array}{l}\mathbf{0 . 0 4} \\
(0.01)\end{array}$ & $\begin{array}{l}\mathbf{0 . 1 6} \\
(0.00)\end{array}$ & $\begin{array}{c}0.07 \\
(0.26)\end{array}$ & $\begin{array}{l}\mathbf{0 . 0 6} \\
(0.01)\end{array}$ & $\begin{array}{l}\mathbf{0 . 3 5} \\
(0.00)\end{array}$ & $\begin{array}{l}\mathbf{0 . 2 9} \\
(0.15)\end{array}$ \\
\hline & 3. Full model & $\begin{array}{l}\mathbf{0 . 1 2} \\
(0.00)\end{array}$ & $\begin{array}{l}\mathbf{0 . 4 5} \\
(0.00)\end{array}$ & $\begin{array}{l}\mathbf{0 . 5 0} \\
(0.16)\end{array}$ & $\begin{array}{l}\mathbf{0 . 0 7} \\
(0.01)\end{array}$ & $\begin{array}{l}\mathbf{0 . 3 8} \\
(0.00)\end{array}$ & $\begin{array}{l}\mathbf{0 . 2 9} \\
(0.00)\end{array}$ \\
\hline & 1. Only $\widehat{p y}$ & $\begin{array}{c}0.00 \\
(0.35)\end{array}$ & $\begin{array}{c}0.03 \\
(0.16)\end{array}$ & $\begin{array}{c}0.04 \\
(0.20)\end{array}$ & $\begin{array}{l}\mathbf{0 . 0 6} \\
(0.00)\end{array}$ & $\begin{array}{l}\mathbf{0 . 2 0} \\
(0.00)\end{array}$ & $\begin{array}{l}\mathbf{0 . 2 4} \\
(0.00)\end{array}$ \\
\hline \multirow[t]{3}{*}{ Germany } & 2. Only controls & $\begin{array}{l}\mathbf{0 . 0 4} \\
(0.00)\end{array}$ & $\begin{array}{l}\mathbf{0 . 0 7} \\
(0.01)\end{array}$ & $\begin{array}{l}\mathbf{0 . 0 2} \\
(0.03)\end{array}$ & $\begin{array}{l}\mathbf{0 . 0 2} \\
(0.00)\end{array}$ & $\begin{array}{l}\mathbf{0 . 1 2} \\
(0.00)\end{array}$ & $\begin{array}{l}\mathbf{0 . 2 3} \\
(0.00)\end{array}$ \\
\hline & 3. Full model & $\begin{array}{l}\mathbf{0 . 0 4} \\
(0.00)\end{array}$ & $\begin{array}{l}\mathbf{0 . 1 3} \\
(0.00)\end{array}$ & $\begin{array}{l}\mathbf{0 . 0 9} \\
(0.08)\end{array}$ & $\begin{array}{l}\mathbf{0 . 0 7} \\
(0.00)\end{array}$ & $\begin{array}{l}\mathbf{0 . 2 8} \\
(0.00)\end{array}$ & $\begin{array}{c}\mathbf{0 . 4 0} \\
(0.00)\end{array}$ \\
\hline & 1. Only $\widehat{p y}$ & $\begin{array}{l}\mathbf{0 . 0 5} \\
(0.01)\end{array}$ & $\begin{array}{l}\mathbf{0 . 2 8} \\
(0.00)\end{array}$ & $\begin{array}{l}\mathbf{0 . 4 7} \\
(0.00)\end{array}$ & $\begin{array}{c}0.02 \\
(0.18)\end{array}$ & $\begin{array}{l}0.01 \\
(0.67)\end{array}$ & $\begin{array}{r}-0.00 \\
(0.91)\end{array}$ \\
\hline \multirow[t]{2}{*}{ Italy } & 2. Only controls & $\begin{array}{l}\mathbf{0 . 0 4} \\
(0.03)\end{array}$ & $\begin{array}{l}\mathbf{0 . 1 9} \\
(0.01)\end{array}$ & $\begin{array}{l}\mathbf{0 . 2 9} \\
(0.01)\end{array}$ & $\begin{array}{c}0.02 \\
(0.25)\end{array}$ & $\begin{array}{l}\mathbf{0 . 2 8} \\
(0.00)\end{array}$ & $\begin{array}{l}\mathbf{0 . 2 7} \\
(0.00)\end{array}$ \\
\hline & 3. Full model & $\begin{array}{l}\mathbf{0 . 0 9} \\
(0.04)\end{array}$ & $\begin{array}{l}\mathbf{0 . 3 9} \\
(0.00)\end{array}$ & $\begin{array}{l}\mathbf{0 . 5 6} \\
(0.00)\end{array}$ & $\begin{array}{l}\mathbf{0 . 0 2} \\
(0.27)\end{array}$ & $\begin{array}{l}\mathbf{0 . 2 7} \\
(0.00)\end{array}$ & $\begin{array}{c}\mathbf{0 . 2 6} \\
(0.00)\end{array}$ \\
\hline
\end{tabular}


Table 5. Continued

\begin{tabular}{|c|c|c|c|c|c|c|c|}
\hline & & \multicolumn{3}{|c|}{ Real returns } & \multicolumn{3}{|c|}{ Changes in real activity } \\
\hline & & $3 \mathrm{mth}$ & $12 \mathrm{mth}$ & $24 \mathrm{mth}$ & $3 \mathrm{mth}$ & $12 \mathrm{mth}$ & $24 \mathrm{mth}$ \\
\hline & 1. Only $\widehat{p y}$ & $\begin{array}{l}0.01 \\
(0.23)\end{array}$ & $\begin{array}{l}0.05 \\
(0.18)\end{array}$ & $\begin{array}{l}0.10 \\
(0.08)\end{array}$ & $\begin{array}{l}\mathbf{0 . 0 7} \\
(0.00)\end{array}$ & $\begin{array}{l}\mathbf{0 . 0 7} \\
(0.06)\end{array}$ & $\begin{array}{c}0.02 \\
(0.44)\end{array}$ \\
\hline \multirow[t]{3}{*}{ Japan } & 2. Only controls & $\begin{array}{l}\mathbf{0 . 0 3} \\
(0.07)\end{array}$ & $\begin{array}{l}0.09 \\
(0.14)\end{array}$ & $\begin{array}{l}0.15 \\
(0.13)\end{array}$ & $\begin{array}{l}\mathbf{0 . 2 0} \\
(0.00)\end{array}$ & $\begin{array}{l}\mathbf{0 . 2 8} \\
(0.00)\end{array}$ & $\begin{array}{l}\mathbf{0 . 2 6} \\
(0.00)\end{array}$ \\
\hline & 3. Full model & $\begin{array}{l}\mathbf{0 . 0 4} \\
(0.06)\end{array}$ & $\begin{array}{l}0.13 \\
(0.11)\end{array}$ & $\begin{array}{l}\mathbf{0 . 2 2} \\
(0.06)\end{array}$ & $\begin{array}{l}\mathbf{0 . 2 4} \\
(0.00)\end{array}$ & $\begin{array}{l}\mathbf{0 . 3 2} \\
(0.00)\end{array}$ & $\begin{array}{l}\mathbf{0 . 2 7} \\
(0.00)\end{array}$ \\
\hline & 1. Only $\widehat{p y}$ & $\begin{array}{l}\mathbf{0 . 0 7} \\
(0.00)\end{array}$ & $\begin{array}{l}\mathbf{0 . 2 3} \\
(0.00)\end{array}$ & $\begin{array}{l}\mathbf{0 . 4 0} \\
(0.00)\end{array}$ & $\begin{array}{l}\mathbf{0 . 0 1} \\
(0.07)\end{array}$ & $\begin{array}{c}0.03 \\
(0.23)\end{array}$ & $\begin{array}{r}0.00 \\
(0.65)\end{array}$ \\
\hline \multirow[t]{3}{*}{ Netherl. } & 2. Only controls & $\begin{array}{l}0.00 \\
(0.26)\end{array}$ & $\begin{array}{c}0.09 \\
(0.15)\end{array}$ & $\begin{array}{l}\mathbf{0 . 1 0} \\
(0.01)\end{array}$ & $\begin{array}{l}0.00 \\
(0.10)\end{array}$ & $\begin{array}{l}\mathbf{0 . 0 6} \\
(0.01)\end{array}$ & $\begin{array}{l}\mathbf{0 . 1 3} \\
(0.00)\end{array}$ \\
\hline & 3. Full model & $\begin{array}{l}\mathbf{0 . 0 6} \\
(0.00)\end{array}$ & $\begin{array}{l}\mathbf{0 . 2 3} \\
(0.00)\end{array}$ & $\begin{array}{l}\mathbf{0 . 4 1} \\
(0.00)\end{array}$ & $\begin{array}{l}0.00 \\
(0.14)\end{array}$ & $\begin{array}{l}\mathbf{0 . 0 7} \\
(0.01)\end{array}$ & $\begin{array}{l}\mathbf{0 . 1 4} \\
(0.00)\end{array}$ \\
\hline & 1. Only $\widehat{p y}$ & $\begin{array}{l}\mathbf{0 . 0 7} \\
(0.00)\end{array}$ & $\begin{array}{l}\mathbf{0 . 3 5} \\
(0.00)\end{array}$ & $\begin{array}{l}\mathbf{0 . 5 7} \\
(0.00)\end{array}$ & $\begin{array}{r}-0.00 \\
(0.55)\end{array}$ & $\begin{array}{r}-0.04 \\
(0.59)\end{array}$ & $\begin{array}{l}\mathbf{0 . 0 4} \\
(0.05)\end{array}$ \\
\hline \multirow[t]{3}{*}{ Norway } & 2. Only controls & $\begin{array}{l}\mathbf{0 . 0 1} \\
(0.01)\end{array}$ & $\begin{array}{l}0.03 \\
(0.65)\end{array}$ & $\begin{array}{l}\mathbf{0 . 0 5} \\
(0.09)\end{array}$ & $\begin{array}{l}\mathbf{0 . 0 0} \\
(0.04)\end{array}$ & $\begin{array}{l}0.05 \\
(0.12)\end{array}$ & $\begin{array}{l}\mathbf{0 . 0 7} \\
(0.07)\end{array}$ \\
\hline & 3. Full model & $\begin{array}{l}\mathbf{0 . 2 1} \\
(0.00)\end{array}$ & $\begin{array}{l}\mathbf{0 . 3 5} \\
(0.00)\end{array}$ & $\begin{array}{l}\mathbf{0 . 4 0} \\
(0.00)\end{array}$ & $\begin{array}{l}\mathbf{0 . 0 0} \\
(0.03)\end{array}$ & $\begin{array}{l}\mathbf{0 . 1 0} \\
(0.00)\end{array}$ & $\begin{array}{l}\mathbf{0 . 1 2} \\
(0.00)\end{array}$ \\
\hline & 1. Only $\widehat{p y}$ & $\begin{array}{l}0.00 \\
(0.29)\end{array}$ & $\begin{array}{l}0.03 \\
(0.12)\end{array}$ & $\begin{array}{l}0.04 \\
(0.20)\end{array}$ & $\begin{array}{l}\mathbf{0 . 0 4} \\
(0.02)\end{array}$ & $\begin{array}{l}\mathbf{0 . 1 4} \\
(0.00)\end{array}$ & $\begin{array}{l}\mathbf{0 . 1 4} \\
(0.01)\end{array}$ \\
\hline \multirow[t]{3}{*}{ Sweden } & 2. Only controls & $\begin{array}{r}-0.00 \\
(0.62)\end{array}$ & $\begin{array}{r}-0.01 \\
(0.74)\end{array}$ & $\begin{array}{l}0.03 \\
(0.15)\end{array}$ & $\begin{array}{l}\mathbf{0 . 1 0} \\
(0.00)\end{array}$ & $\begin{array}{l}\mathbf{0 . 3 2} \\
(0.00)\end{array}$ & $\begin{array}{l}\mathbf{0 . 2 6} \\
(0.00)\end{array}$ \\
\hline & 3. Full model & $\begin{array}{l}\mathbf{0 . 0 4}^{a} \\
(0.07)\end{array}$ & $\begin{array}{l}\mathbf{0 . 2 6}^{a} \\
(0.00)\end{array}$ & $\begin{array}{l}\mathbf{0 . 4 0 ^ { a }} \\
(0.16)\end{array}$ & $\begin{array}{l}\mathbf{0 . 1 1}^{a} \\
(0.00)\end{array}$ & $\begin{array}{l}\mathbf{0 . 3 2}^{a} \\
(0.00)\end{array}$ & $\begin{array}{l}\mathbf{0 . 2 6}^{a} \\
(0.00)\end{array}$ \\
\hline & 1. Only $\widehat{p y}$ & $\begin{array}{c}0.03 \\
(0.15)\end{array}$ & $\begin{array}{l}\mathbf{0 . 1 2} \\
(0.04)\end{array}$ & $\begin{array}{l}0.08 \\
(0.19)\end{array}$ & $\begin{array}{l}\mathbf{0 . 0 4} \\
(0.02)\end{array}$ & $\begin{array}{l}\mathbf{0 . 0 9} \\
(0.07)\end{array}$ & $\begin{array}{c}0.02 \\
(0.50)\end{array}$ \\
\hline \multirow[t]{3}{*}{ UK } & 2. Only controls & $\begin{array}{l}0.00 \\
(0.70)\end{array}$ & $\begin{array}{l}0.06 \\
(0.15)\end{array}$ & $\begin{array}{l}0.07 \\
(0.17)\end{array}$ & $\begin{array}{l}0.03 \\
(0.14)\end{array}$ & $\begin{array}{l}\mathbf{0 . 1 9} \\
(0.00)\end{array}$ & $\begin{array}{l}\mathbf{0 . 3 1} \\
(0.00)\end{array}$ \\
\hline & 3. Full model & $\begin{array}{l}0.05 \\
(0.20)\end{array}$ & $\begin{array}{l}\mathbf{0 . 2 4} \\
(0.00)\end{array}$ & $\begin{array}{l}\mathbf{0 . 3 1} \\
(0.08)\end{array}$ & $\begin{array}{l}0.04 \\
(0.13)\end{array}$ & $\begin{array}{l}\mathbf{0 . 2 1} \\
(0.00)\end{array}$ & $\begin{array}{l}\mathbf{0 . 3 1} \\
(0.00)\end{array}$ \\
\hline & 1. Only $\widehat{p y}$ & $\begin{array}{l}\mathbf{0 . 0 7} \\
(0.00)\end{array}$ & $\begin{array}{l}\mathbf{0 . 2 6} \\
(0.00)\end{array}$ & $\begin{array}{l}\mathbf{0 . 4 0} \\
(0.00)\end{array}$ & $\begin{array}{l}\mathbf{0 . 0 3} \\
(0.03)\end{array}$ & $\begin{array}{l}0.00 \\
(0.73)\end{array}$ & $\begin{array}{r}-0.00 \\
(0.96)\end{array}$ \\
\hline \multirow[t]{2}{*}{ US } & 2. Only controls & $\begin{array}{l}0.03 \\
(0.17)\end{array}$ & $\begin{array}{l}\mathbf{0 . 1 8} \\
(0.01)\end{array}$ & $\begin{array}{l}0.07 \\
(0.41)\end{array}$ & $\begin{array}{l}0.26 \\
(0.00)\end{array}$ & $\begin{array}{l}\mathbf{0 . 3 0} \\
(0.00)\end{array}$ & $\begin{array}{l}\mathbf{0 . 3 5} \\
(0.00)\end{array}$ \\
\hline & 3. Full model & $\begin{array}{l}\mathbf{0 . 1 0} \\
(0.00)\end{array}$ & $\begin{array}{l}\mathbf{0 . 3 9} \\
(0.00)\end{array}$ & $\begin{array}{l}\mathbf{0 . 4 7} \\
(0.00)\end{array}$ & $\begin{array}{l}\mathbf{0 . 2 6} \\
(0.00)\end{array}$ & $\begin{array}{l}\mathbf{0 . 3 0} \\
(0.00)\end{array}$ & $\begin{array}{l}\mathbf{0 . 3 5} \\
(0.00) \\
\end{array}$ \\
\hline
\end{tabular}

Notes: See separate page with notes to tables. 
Table 6. The distribution of the simulated $\bar{R}^{2}$ s

\begin{tabular}{|c|c|c|c|c|c|}
\hline & \multirow[b]{2}{*}{$k$} & \multicolumn{2}{|c|}{ Fractiles of empirical distribution } & \multirow[b]{2}{*}{ mean } & \multirow[b]{2}{*}{$\bar{R}^{2}$} \\
\hline & & $(0.05,0.95)$ & $(0.01,0.99)$ & & \\
\hline \multirow[t]{4}{*}{ Belgium } & 1 & $(-0.003,0.009)$ & $(-0.003,0.018)$ & 0.000 & 0.028 \\
\hline & 3 & $(-0.003,0.030)$ & $(-0.003,0.054)$ & 0.006 & 0.086 \\
\hline & 12 & $(-0.003,0.104)$ & $(-0.003,0.167)$ & 0.025 & 0.281 \\
\hline & 24 & $(-0.003,0.171)$ & $(-0.003,0.264)$ & 0.043 & 0.340 \\
\hline \multirow[t]{4}{*}{ Canada } & 1 & $(-0.003,0.010)$ & $(-0.003,0.017)$ & 0.000 & 0.030 \\
\hline & 3 & $(-0.003,0.030)$ & $(-0.003,0.055)$ & 0.006 & 0.093 \\
\hline & 12 & $(-0.003,0.100)$ & $(-0.003,0.174)$ & 0.026 & 0.399 \\
\hline & 24 & $(-0.003,0.173)$ & $(-0.003,0.261)$ & 0.043 & 0.462 \\
\hline \multirow[t]{4}{*}{ Denmark } & 1 & $(-0.003,0.010)$ & $(-0.003,0.019)$ & 0.000 & -0.002 \\
\hline & 3 & $(-0.003,0.031)$ & $(-0.003,0.052)$ & 0.006 & 0.009 \\
\hline & 12 & $(-0.003,0.106)$ & $(-0.003,0.171)$ & 0.026 & 0.149 \\
\hline & 24 & $(-0.003,0.173)$ & $(-0.003,0.274)$ & 0.044 & 0.307 \\
\hline \multirow[t]{4}{*}{ France } & 1 & $(-0.003,0.009)$ & $(-0.003,0.017)$ & 0.000 & 0.012 \\
\hline & 3 & $(-0.003,0.031)$ & $(-0.003,0.053)$ & 0.006 & 0.047 \\
\hline & 12 & $(-0.003,0.103)$ & $(-0.003,0.168)$ & 0.025 & 0.246 \\
\hline & 24 & $(-0.003,0.164)$ & $(-0.003,0.253)$ & 0.043 & 0.341 \\
\hline \multirow[t]{4}{*}{ Germany } & 1 & $(-0.003,0.009)$ & $(-0.003,0.019)$ & 0.000 & -0.001 \\
\hline & 3 & $(-0.003,0.030)$ & $(-0.003,0.051)$ & 0.006 & 0.003 \\
\hline & 12 & $(-0.003,0.110)$ & $(-0.003,0.177)$ & 0.026 & 0.034 \\
\hline & 24 & $(-0.003,0.184)$ & $(-0.003,0.279)$ & 0.046 & 0.039 \\
\hline \multirow[t]{4}{*}{ Italy } & 1 & $(-0.003,0.009)$ & $(-0.003,0.018)$ & 0.000 & 0.011 \\
\hline & 3 & $(-0.003,0.030)$ & $(-0.003,0.054)$ & 0.006 & 0.052 \\
\hline & 12 & $(-0.003,0.116)$ & $(-0.003,0.176)$ & 0.028 & 0.284 \\
\hline & 24 & $(-0.003,0.191)$ & $(-0.003,0.298)$ & 0.051 & 0.473 \\
\hline
\end{tabular}


Table 6. Continued

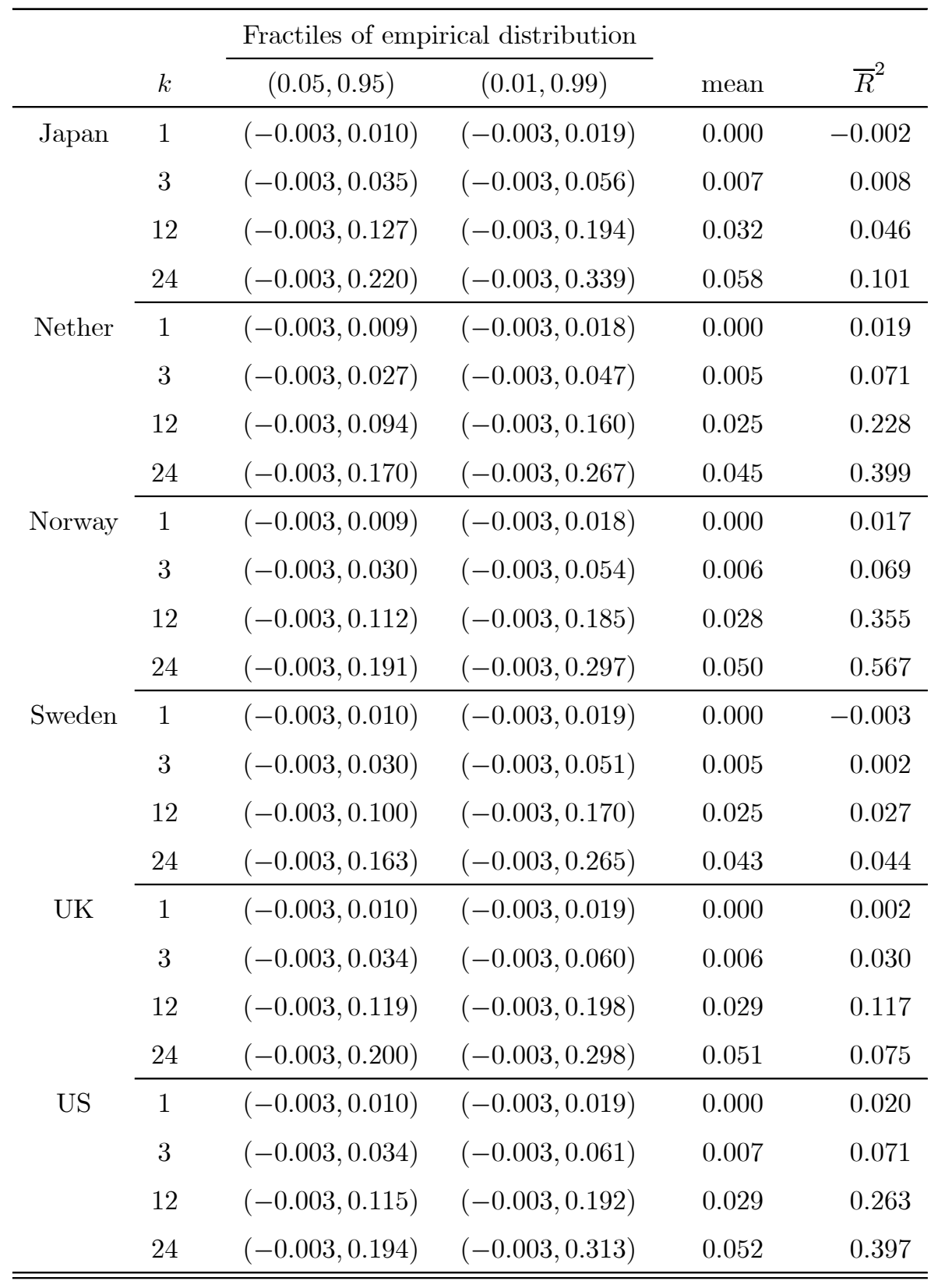

Notes: See separate page with notes to tables. 
Table 7. Out-of-sample forecast statistics. Forecasting real stock returns using either the $\widehat{p y}$-ratios, the dividend yields $(d y)$, or the price-earnings ratio $(p e)$

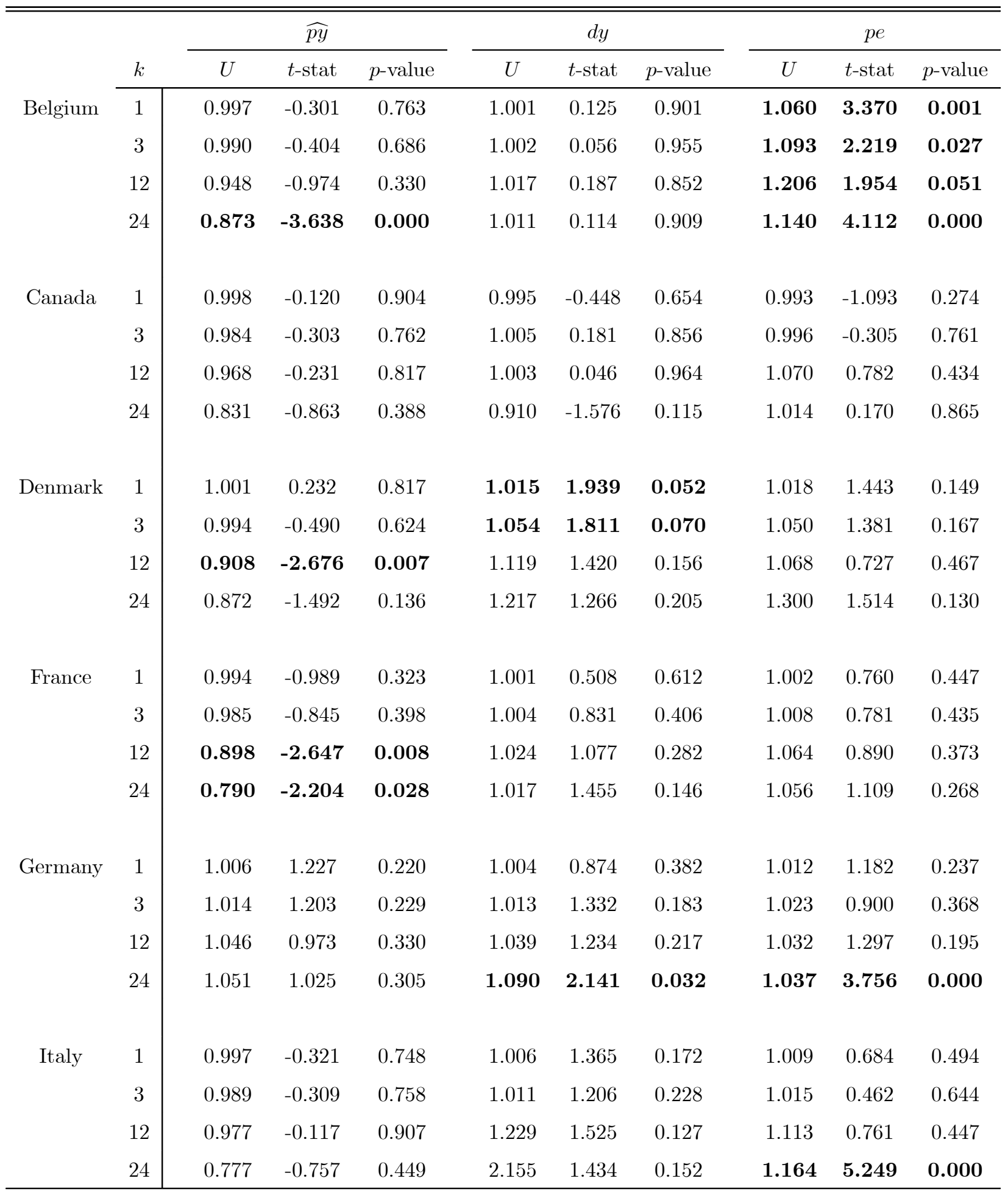


Table 7. Continued

\begin{tabular}{|c|c|c|c|c|c|c|c|c|c|c|}
\hline & \multirow[b]{2}{*}{$k$} & \multicolumn{3}{|c|}{$\widehat{p y}$} & \multicolumn{3}{|c|}{$d y$} & \multicolumn{3}{|c|}{ pe } \\
\hline & & $U$ & $t$-stat & $p$-value & $U$ & $t$-stat & $p$-value & $U$ & $t$-stat & $p$-value \\
\hline \multirow[t]{4}{*}{ Japan } & 1 & 1.019 & 1.766 & 0.077 & 1.001 & 0.331 & 0.741 & 1.003 & 1.636 & 0.102 \\
\hline & 3 & 1.060 & 1.560 & 0.119 & 1.002 & 0.301 & 0.764 & 1.006 & 1.383 & 0.167 \\
\hline & 12 & 1.160 & 1.487 & 0.137 & 0.996 & -0.142 & 0.887 & 0.976 & -1.070 & 0.285 \\
\hline & 24 & 1.491 & 3.467 & 0.001 & 1.034 & 0.302 & 0.762 & 0.929 & -1.205 & 0.228 \\
\hline \multirow[t]{4}{*}{ Nether } & 1 & 0.995 & -0.477 & 0.633 & 1.012 & 1.261 & 0.207 & 0.991 & -0.987 & 0.324 \\
\hline & 3 & 0.987 & -0.436 & 0.663 & 1.049 & 1.812 & 0.070 & 0.999 & -0.089 & 0.929 \\
\hline & 12 & 0.948 & -0.753 & 0.452 & 1.088 & 0.966 & 0.334 & 0.999 & -0.040 & 0.968 \\
\hline & 24 & 0.879 & -1.311 & 0.190 & 1.107 & 0.556 & 0.578 & 0.928 & -2.150 & 0.032 \\
\hline \multirow[t]{4}{*}{ Norway } & 1 & 0.984 & -1.678 & 0.093 & 1.002 & 0.513 & 0.608 & 0.998 & -0.351 & 0.726 \\
\hline & 3 & 0.953 & -1.737 & 0.082 & 1.012 & 0.645 & 0.519 & 1.000 & -0.014 & 0.989 \\
\hline & 12 & 0.835 & -1.807 & 0.071 & 1.111 & 1.286 & 0.198 & 0.957 & -0.752 & 0.452 \\
\hline & 24 & 0.651 & -3.702 & 0.000 & 1.338 & 2.249 & 0.025 & 0.781 & -3.053 & 0.002 \\
\hline \multirow[t]{4}{*}{ Sweden } & 1 & 1.001 & 0.423 & 0.673 & 1.004 & 0.378 & 0.705 & 1.004 & 0.218 & 0.828 \\
\hline & 3 & 0.997 & -0.212 & 0.832 & 1.017 & 0.621 & 0.535 & 1.035 & 1.368 & 0.171 \\
\hline & 12 & 0.964 & -1.439 & 0.150 & 1.093 & 0.627 & 0.531 & 1.096 & 1.251 & 0.211 \\
\hline & 24 & 0.916 & -1.246 & 0.213 & 0.943 & -0.846 & 0.398 & 0.975 & -0.460 & 0.646 \\
\hline \multirow[t]{4}{*}{ UK } & 1 & 1.030 & 1.672 & 0.094 & 0.999 & -0.117 & 0.907 & 1.005 & 0.577 & 0.564 \\
\hline & 3 & 1.086 & 1.316 & 0.188 & 1.003 & 0.144 & 0.885 & 1.021 & 1.035 & 0.301 \\
\hline & 12 & 1.430 & 2.678 & 0.007 & 0.974 & -0.434 & 0.664 & 1.164 & 2.971 & 0.003 \\
\hline & 24 & 0.968 & -1.040 & 0.298 & 0.698 & -3.459 & 0.001 & 1.224 & 1.775 & 0.076 \\
\hline \multirow[t]{4}{*}{ US } & 1 & 0.993 & -1.571 & 0.116 & 1.042 & 3.959 & 0.000 & 1.020 & 3.121 & 0.002 \\
\hline & 3 & 0.979 & -1.209 & 0.226 & 1.089 & 3.545 & 0.000 & 1.051 & 3.175 & 0.001 \\
\hline & 12 & 0.921 & -1.474 & 0.140 & 1.246 & 2.752 & 0.006 & 1.173 & 4.162 & 0.000 \\
\hline & 24 & 0.840 & -2.073 & 0.038 & 1.114 & 1.428 & 0.153 & 1.049 & 0.927 & 0.354 \\
\hline
\end{tabular}


Table 8. Predicting long-horizon changes in MSCI real share price and MSCI real returns

\begin{tabular}{|c|c|c|c|c|c|c|c|c|c|}
\hline & & \multicolumn{4}{|c|}{ Changes in MSCI real share price } & \multicolumn{4}{|c|}{ MSCI real returns } \\
\hline & & $1 \mathrm{mth}$ & $3 \mathrm{mth}$ & $12 \mathrm{mth}$ & $24 \mathrm{mth}$ & $1 \mathrm{mth}$ & $3 \mathrm{mth}$ & $12 \mathrm{mth}$ & $24 \mathrm{mth}$ \\
\hline \multirow[t]{4}{*}{ Belgium } & $\varphi$ & $\begin{array}{c}0.08 \\
(1.78)\end{array}$ & $\begin{array}{l}\mathbf{0 . 3 2} \\
(3.05)\end{array}$ & $\begin{array}{l}\mathbf{1 . 3 8} \\
(3.96)\end{array}$ & $\begin{array}{l}\mathbf{2 . 4 4} \\
(4.51)\end{array}$ & $\begin{array}{c}0.08 \\
(1.78)\end{array}$ & $\begin{array}{l}\mathbf{0 . 3 4} \\
(3.21)\end{array}$ & $\begin{array}{l}\mathbf{1 . 4 2} \\
(4.24)\end{array}$ & $\begin{array}{l}\mathbf{2 . 4 8} \\
(4.94)\end{array}$ \\
\hline & & {$[1.92]$} & {$[2.18]$} & {$[2.62]$} & {$[2.98]$} & {$[1.99]$} & {$[2.17]$} & {$[2.69]$} & {$[3.06]$} \\
\hline & $\bar{R}^{2}$ & $\begin{array}{l}\mathbf{0 . 0 1} \\
(0.07)\end{array}$ & $\begin{array}{l}\mathbf{0 . 0 5} \\
(0.00)\end{array}$ & $\begin{array}{l}\mathbf{0 . 2 1} \\
(0.00)\end{array}$ & $\begin{array}{l}\mathbf{0 . 2 8} \\
(0.00)\end{array}$ & $\begin{array}{c}\mathbf{0 . 0 1} \\
(0.07)\end{array}$ & $\begin{array}{c}\mathbf{0 . 0 5} \\
(0.00)\end{array}$ & $\begin{array}{l}\mathbf{0 . 2 3} \\
(0.00)\end{array}$ & $\underset{(0.00)}{\mathbf{0 . 3 1}}$ \\
\hline & & {$[0.01]$} & {$[0.03]$} & {$[0.10]$} & {$[0.17]$} & {$[0.01]$} & {$[0.03]$} & {$[0.10]$} & {$[0.17]$} \\
\hline \multirow[t]{4}{*}{ Canada } & $\varphi$ & $\begin{array}{l}\mathbf{0 . 0 8} \\
(3.42)\end{array}$ & $\begin{array}{l}\mathbf{0 . 2 3} \\
(4.23)\end{array}$ & $\begin{array}{l}\mathbf{1 . 0 2} \\
(6.12)\end{array}$ & $\begin{array}{l}\mathbf{1 . 4 9} \\
(6.27)\end{array}$ & $\begin{array}{l}\mathbf{0 . 0 7} \\
(3.29)\end{array}$ & $\begin{array}{l}\mathbf{0 . 2 2} \\
(4.10)\end{array}$ & $\begin{array}{l}\mathbf{0 . 9 8} \\
(5.97)\end{array}$ & $\begin{array}{l}\mathbf{1 . 3 9} \\
(5.97)\end{array}$ \\
\hline & & {$[2.17]$} & {$[2.43]$} & {$[3.06]$} & {$[3.64]$} & {$[2.14]$} & {$[2.40]$} & {$[3.05]$} & {$[3.73]$} \\
\hline & $\bar{R}^{2}$ & $\begin{array}{l}\mathbf{0 . 0 3} \\
(0.00)\end{array}$ & $\begin{array}{l}\mathbf{0 . 0 8} \\
(0.00)\end{array}$ & $\begin{array}{l}\mathbf{0 . 3 4} \\
(0.00)\end{array}$ & $\begin{array}{c}\mathbf{0 . 4 6} \\
(0.00)\end{array}$ & $\begin{array}{c}\mathbf{0 . 0 2} \\
(0.00)\end{array}$ & $\underset{(0.00)}{\mathbf{0 . 0 8}}$ & $\begin{array}{l}\mathbf{0 . 3 3} \\
(5.97)\end{array}$ & $\begin{array}{c}\mathbf{0 . 4 3} \\
(0.00)\end{array}$ \\
\hline & & {$[0.01]$} & {$[0.03]$} & {$[0.12]$} & {$[0.20]$} & {$[0.01]$} & {$[0.03]$} & {$[0.12]$} & {$[0.20]$} \\
\hline \multirow[t]{4}{*}{ Denmark } & $\varphi$ & $\begin{array}{c}0.04 \\
(1.67)\end{array}$ & $\begin{array}{l}\mathbf{0 . 1 5} \\
(2.35)\end{array}$ & $\begin{array}{l}\mathbf{0 . 8 2} \\
(3.41)\end{array}$ & $\begin{array}{l}\mathbf{1 . 5 0} \\
(4.80)\end{array}$ & $\begin{array}{c}0.04 \\
(1.54)\end{array}$ & $\begin{array}{l}\mathbf{0 . 1 5} \\
(2.30)\end{array}$ & $\begin{array}{l}\mathbf{0 . 8 0} \\
(3.25)\end{array}$ & $\begin{array}{l}\mathbf{1 . 4 5} \\
(4.57)\end{array}$ \\
\hline & & {$[2.01]$} & {$[2.25]$} & {$[2.74]$} & [3.19] & {$[2.01]$} & {$[2.29]$} & {$[2.86]$} & {$[3.22]$} \\
\hline & $\bar{R}^{2}$ & $\begin{array}{l}\mathbf{0 . 0 1} \\
(0.09)\end{array}$ & $\begin{array}{l}\mathbf{0 . 0 3} \\
(0.02)\end{array}$ & $\begin{array}{l}\mathbf{0 . 1 8} \\
(0.00)\end{array}$ & $\begin{array}{l}\mathbf{0 . 3 5} \\
(0.00)\end{array}$ & $\begin{array}{l}0.00 \\
(0.12)\end{array}$ & $\begin{array}{l}\mathbf{0 . 0 3} \\
(0.02)\end{array}$ & $\begin{array}{l}\mathbf{0 . 1 7} \\
(0.00)\end{array}$ & $\begin{array}{l}\mathbf{0 . 3 5} \\
(0.00)\end{array}$ \\
\hline & & {$[0.01]$} & {$[0.03]$} & {$[0.11]$} & {$[0.18]$} & {$[0.01]$} & {$[0.03]$} & {$[0.11]$} & {$[0.18]$} \\
\hline \multirow[t]{4}{*}{ France } & $\varphi$ & $\begin{array}{l}\mathbf{0 . 1 2} \\
(2.24)\end{array}$ & $\begin{array}{l}\mathbf{0 . 4 8} \\
(3.75)\end{array}$ & $\begin{array}{l}\mathbf{2 . 1 7} \\
(4.11)\end{array}$ & $\begin{array}{l}\mathbf{3 . 0 5} \\
(4.41)\end{array}$ & $\begin{array}{l}\mathbf{0 . 1 3} \\
(2.22)\end{array}$ & $\begin{array}{l}\mathbf{0 . 4 9} \\
(3.83)\end{array}$ & $\begin{array}{l}\mathbf{2 . 1 8} \\
(4.25)\end{array}$ & $\begin{array}{l}\mathbf{2 . 9 9} \\
(4.93)\end{array}$ \\
\hline & & [1.92] & {$[2.23]$} & {$[2.66]$} & {$[3.08]$} & [1.96] & {$[2.22]$} & {$[2.71]$} & {$[3.17]$} \\
\hline & $\bar{R}^{2}$ & $\begin{array}{l}\mathbf{0 . 0 1} \\
(0.02)\end{array}$ & $\begin{array}{l}\mathbf{0 . 0 6} \\
(0.00)\end{array}$ & $\begin{array}{l}\mathbf{0 . 2 5} \\
(0.00)\end{array}$ & $\begin{array}{l}\mathbf{0 . 3 0} \\
(0.00)\end{array}$ & $\begin{array}{l}\mathbf{0 . 0 1} \\
(0.03)\end{array}$ & $\begin{array}{l}\mathbf{0 . 0 6} \\
(0.00)\end{array}$ & $\begin{array}{l}\mathbf{0 . 2 7} \\
(0.00)\end{array}$ & $\begin{array}{l}\mathbf{0 . 3 2} \\
(0.00)\end{array}$ \\
\hline & & {$[0.01]$} & {$[0.03]$} & {$[0.10]$} & {$[0.17]$} & {$[0.01]$} & {$[0.03]$} & {$[0.10]$} & {$[0.7]$} \\
\hline \multirow[t]{4}{*}{ Germany } & $\varphi$ & $\begin{array}{l}0.04 \\
(0.85)\end{array}$ & $\begin{array}{c}0.12 \\
(1.06)\end{array}$ & $\begin{array}{c}0.58 \\
(1.27)\end{array}$ & $\begin{array}{c}0.79 \\
(1.10)\end{array}$ & $\begin{array}{l}0.04 \\
(0.81)\end{array}$ & $\begin{array}{c}\mathbf{0 . 1 3} \\
(1.16)\end{array}$ & $\begin{array}{c}0.60 \\
(1.33)\end{array}$ & $\begin{array}{c}0.81 \\
(1.13)\end{array}$ \\
\hline & & {$[2.01]$} & {$[2.30]$} & {$[2.82]$} & [3.33] & {$[2.01]$} & {$[2.30]$} & {$[2.79]$} & {$[3.27]$} \\
\hline & $\bar{R}^{2}$ & $-\begin{array}{r}0.00 \\
(0.40)\end{array}$ & $\begin{array}{l}0.00 \\
(0.29)\end{array}$ & $\begin{array}{l}0.03 \\
(0.20)\end{array}$ & $\begin{array}{l}0.03 \\
(0.27)\end{array}$ & $\begin{array}{r}-0.00 \\
(0.42)\end{array}$ & $\begin{array}{l}0.00 \\
(0.23)\end{array}$ & $\begin{array}{l}0.03 \\
(0.18)\end{array}$ & $\begin{array}{c}0.03 \\
(0.26)\end{array}$ \\
\hline & & {$[0.01]$} & {$[0.03]$} & {$[0.11]$} & {$[0.19]$} & {$[0.01]$} & {$[0.03]$} & {$[0.11]$} & {$[0.18]$} \\
\hline \multirow[t]{4}{*}{ Italy } & $\varphi$ & $\begin{array}{l}\mathbf{0 . 0 7} \\
(2.07)\end{array}$ & $\begin{array}{l}\mathbf{0 . 2 2} \\
(2.53)\end{array}$ & $\begin{array}{l}\mathbf{1 . 2 2} \\
(4.87)\end{array}$ & $\begin{array}{c}\mathbf{2 . 3 4} \\
(10.12)\end{array}$ & $\begin{array}{l}\mathbf{0 . 0 7} \\
(2.02)\end{array}$ & $\begin{array}{l}\mathbf{0 . 2 2} \\
(2.52)\end{array}$ & $\begin{array}{l}\mathbf{1 . 2 2} \\
(4.87)\end{array}$ & $\begin{array}{c}\mathbf{2 . 3 2} \\
(10.29)\end{array}$ \\
\hline & & {$[2.07]$} & {$[2.40]$} & {$[2.89]$} & {$[3.89]$} & {$[2.05]$} & {$[2.38]$} & {$[2.95]$} & {$[3.38]$} \\
\hline & $\bar{R}^{2}$ & $\begin{array}{l}\mathbf{0 . 0 1} \\
(0.04)\end{array}$ & $\begin{array}{l}\mathbf{0 . 0 5} \\
(0.01)\end{array}$ & $\begin{array}{l}\mathbf{0 . 2 7} \\
(0.00)\end{array}$ & $\begin{array}{l}\mathbf{0 . 4 7} \\
(0.00)\end{array}$ & $\begin{array}{c}\mathbf{0 . 0 1} \\
(0.04)\end{array}$ & $\begin{array}{c}\mathbf{0 . 0 5} \\
(0.01)\end{array}$ & $\begin{array}{l}\mathbf{0 . 2 7} \\
(0.00)\end{array}$ & $\begin{array}{l}\mathbf{0 . 4 7} \\
(0.00)\end{array}$ \\
\hline & & {$[0.01]$} & {$[0.03]$} & {$[0.11]$} & {$[0.20]$} & {$[0.01]$} & {$[0.03]$} & {$[0.12]$} & {$[0.20]$} \\
\hline
\end{tabular}


Table 8. Continued

\begin{tabular}{|c|c|c|c|c|c|c|c|c|c|}
\hline & & \multicolumn{4}{|c|}{ Changes in MSCI real share prices } & \multicolumn{4}{|c|}{ MSCI real returns } \\
\hline & & $1 \mathrm{mth}$ & $3 \mathrm{mth}$ & $12 \mathrm{mth}$ & $24 \mathrm{mth}$ & $1 \mathrm{mth}$ & $3 \mathrm{mth}$ & $12 \mathrm{mth}$ & $24 \mathrm{mth}$ \\
\hline \multirow[t]{4}{*}{ Japan } & $\varphi$ & $\begin{array}{c}0.03 \\
(1.22)\end{array}$ & $\begin{array}{c}0.11 \\
(1.58)\end{array}$ & $\begin{array}{l}0.48 \\
(1.63)\end{array}$ & $\begin{array}{c}0.89 \\
(1.95)\end{array}$ & $\begin{array}{c}0.03 \\
(1.08)\end{array}$ & $\begin{array}{c}0.11 \\
(1.54)\end{array}$ & $\begin{array}{c}0.46 \\
(1.58)\end{array}$ & $\begin{array}{l}0.86 \\
(1.88)\end{array}$ \\
\hline & & {$[2.20]$} & {$[2.51]$} & {$[3.15]$} & {$[3.78]$} & {$[2.18]$} & {$[2.46]$} & {$[3.06]$} & {$[3.75]$} \\
\hline & $\bar{R}^{2}$ & $\begin{array}{l}0.00 \\
(0.22)\end{array}$ & $\begin{array}{c}0.02 \\
(0.11)\end{array}$ & $\begin{array}{l}0.07 \\
(0.10)\end{array}$ & $\begin{array}{l}0.12 \\
(0.05)\end{array}$ & $\begin{array}{l}0.00 \\
(0.28)\end{array}$ & $\begin{array}{c}0.01 \\
(0.12)\end{array}$ & $\begin{array}{l}0.06 \\
(0.11)\end{array}$ & $\begin{array}{c}0.11 \\
(0.06)\end{array}$ \\
\hline & & {$[0.01]$} & {$[0.04]$} & {$[0.13]$} & {$[0.22]$} & {$[0.01]$} & {$[0.03]$} & {$[0.13]$} & {$[0.22]$} \\
\hline \multirow[t]{4}{*}{ Netherl. } & $\varphi$ & $\begin{array}{l}0.06 \\
(1.01)\end{array}$ & $\begin{array}{l}0.31 \\
(1.90)\end{array}$ & $\begin{array}{l}1.20 \\
(1.76)\end{array}$ & $\begin{array}{c}1.92 \\
(1.72)\end{array}$ & $\begin{array}{l}0.08 \\
(1.26)\end{array}$ & $\begin{array}{l}0.32 \\
(1.97)\end{array}$ & $\begin{array}{l}1.23 \\
(1.89)\end{array}$ & $\begin{array}{l}1.95 \\
(1.93)\end{array}$ \\
\hline & & {$[1.81]$} & {$[2.03]$} & {$[2.39]$} & {$[2.65]$} & {$[1.76]$} & {$[2.00]$} & {$[2.48]$} & {$[2.69]$} \\
\hline & $\bar{R}^{2}$ & $\begin{array}{l}0.00 \\
(0.31)\end{array}$ & $\begin{array}{c}\mathbf{0 . 0 2} \\
(0.06)\end{array}$ & $\begin{array}{l}\mathbf{0 . 0 9} \\
(0.08)\end{array}$ & $\begin{array}{l}\mathbf{0 . 1 4} \\
(0.09)\end{array}$ & $\begin{array}{l}0.00 \\
(0.21)\end{array}$ & $\begin{array}{c}\mathbf{0 . 0 2} \\
(0.05)\end{array}$ & $\begin{array}{l}\mathbf{0 . 1 0} \\
(0.06)\end{array}$ & $\begin{array}{l}\mathbf{0 . 1 5} \\
(0.05)\end{array}$ \\
\hline & & {$[0.01]$} & {$[0.02]$} & {$[0.08]$} & {$[0.12]$} & {$[0.01]$} & {$[0.02]$} & {$[0.08]$} & {$[0.12]$} \\
\hline \multirow[t]{4}{*}{ Norway } & $\varphi$ & $\begin{array}{l}0.03 \\
(1.87)\end{array}$ & $\begin{array}{l}\mathbf{0 . 1 2} \\
(2.91)\end{array}$ & $\begin{array}{l}\mathbf{0 . 5 7} \\
(4.97)\end{array}$ & $\begin{array}{l}\mathbf{0 . 9 7} \\
(6.48)\end{array}$ & $\begin{array}{l}0.03 \\
(1.85)\end{array}$ & $\begin{array}{l}\mathbf{0 . 1 2} \\
(2.98)\end{array}$ & $\begin{array}{l}\mathbf{0 . 5 7} \\
(5.03)\end{array}$ & $\begin{array}{l}\mathbf{0 . 9 7} \\
(6.47)\end{array}$ \\
\hline & & {$[2.04]$} & {$[2.29]$} & {$[2.87]$} & {$[3.46]$} & {$[2.12]$} & {$[2.40]$} & {$[2.95]$} & [3.59] \\
\hline & $\bar{R}^{2}$ & $\begin{array}{l}\mathbf{0 . 0 2} \\
(0.01)\end{array}$ & $\begin{array}{c}\mathbf{0 . 0 8} \\
(0.00)\end{array}$ & $\begin{array}{l}\mathbf{0 . 3 9} \\
(0.00)\end{array}$ & $\begin{array}{c}\mathbf{0 . 6 2} \\
(0.00)\end{array}$ & $\begin{array}{c}\mathbf{0 . 0 2} \\
(0.06)\end{array}$ & $\begin{array}{l}\mathbf{0 . 0 8} \\
(0.00)\end{array}$ & $\begin{array}{l}\mathbf{0 . 4 0} \\
(0.00)\end{array}$ & $\begin{array}{l}\mathbf{0 . 6 3} \\
(0.00)\end{array}$ \\
\hline & & {$[0.01]$} & {$[0.03]$} & {$[0.11]$} & {$[0.20]$} & {$[0.01]$} & {$[0.03]$} & {$[0.12]$} & {$[0.20]$} \\
\hline \multirow[t]{4}{*}{ Sweden } & $\varphi$ & $\begin{array}{r}-0.02 \\
(0.43)\end{array}$ & $\begin{array}{c}0.13 \\
(1.03)\end{array}$ & $\begin{array}{c}0.86 \\
(1.78)\end{array}$ & $\begin{array}{l}1.39 \\
(1.70)\end{array}$ & $\begin{array}{r}-0.01 \\
(0.23)\end{array}$ & $\begin{array}{c}0.16 \\
(1.23)\end{array}$ & $\begin{array}{l}\mathbf{0 . 9 8} \\
(2.03)\end{array}$ & $\begin{array}{l}\mathbf{1 . 5 7} \\
(1.97)\end{array}$ \\
\hline & & [1.99] & {$[2.24]$} & {$[2.68]$} & {$[3.02]$} & [1.89] & {$[2.13]$} & {$[2.61]$} & [3.01] \\
\hline & $\bar{R}^{2}$ & $\begin{array}{r}-0.00 \\
(0.66)\end{array}$ & $\begin{array}{l}0.00 \\
(0.30)\end{array}$ & $\begin{array}{l}0.03 \\
(0.08)\end{array}$ & $\begin{array}{l}0.05 \\
(0.09)\end{array}$ & $\begin{array}{r}-0.02 \\
(0.82)\end{array}$ & $\begin{array}{l}0.00 \\
(0.22)\end{array}$ & $\begin{array}{l}\mathbf{0 . 0 5} \\
(0.04)\end{array}$ & $\begin{array}{l}\mathbf{0 . 0 7} \\
(0.05)\end{array}$ \\
\hline & & {$[0.01]$} & {$[0.03]$} & {$[0.10]$} & {$[0.16]$} & {$[0.01]$} & {$[0.03]$} & {$[0.09]$} & {$[0.16]$} \\
\hline \multirow[t]{4}{*}{ UK } & $\varphi$ & $\begin{array}{l}\mathbf{0 . 2 2} \\
(2.46)\end{array}$ & $\begin{array}{l}\mathbf{0 . 6 2} \\
(3.27)\end{array}$ & $\begin{array}{l}\mathbf{2 . 3 1} \\
(3.12)\end{array}$ & $\begin{array}{l}\mathbf{1 . 9 0} \\
(1.93)\end{array}$ & $\begin{array}{l}\mathbf{0 . 2 1} \\
(2.46)\end{array}$ & $\begin{array}{l}\mathbf{0 . 6 2} \\
(3.28)\end{array}$ & $\begin{array}{l}\mathbf{2 . 3 1} \\
(3.13)\end{array}$ & $\begin{array}{l}\mathbf{1 . 8 9} \\
(1.95)\end{array}$ \\
\hline & & [1.90] & {$[2.17]$} & {$[2.65]$} & [2.99] & [1.93] & {$[2.16]$} & {$[2.66]$} & [3.03] \\
\hline & $\bar{R}^{2}$ & $\begin{array}{l}\mathbf{0 . 0 3} \\
(0.01)\end{array}$ & $\begin{array}{l}\mathbf{0 . 0 8} \\
(0.00)\end{array}$ & $\begin{array}{l}\mathbf{0 . 3 1} \\
(0.00)\end{array}$ & $\begin{array}{l}\mathbf{0 . 2 0} \\
(0.05)\end{array}$ & $\begin{array}{c}\mathbf{0 . 0 3} \\
(0.01)\end{array}$ & $\begin{array}{l}\mathbf{0 . 0 8} \\
(0.00)\end{array}$ & $\begin{array}{l}\mathbf{0 . 3 1} \\
(0.00)\end{array}$ & $\begin{array}{l}\mathbf{0 . 2 0} \\
(0.05)\end{array}$ \\
\hline & & {$[0.01]$} & {$[0.03]$} & {$[0.08]$} & {$[0.12]$} & {$[0.01]$} & {$[0.03]$} & {$[0.09]$} & {$[0.13]$} \\
\hline \multirow[t]{4}{*}{ US } & $\varphi$ & $\begin{array}{l}\mathbf{0 . 0 7} \\
(3.00)\end{array}$ & $\begin{array}{l}\mathbf{0 . 2 0} \\
(3.37)\end{array}$ & $\begin{array}{l}\mathbf{0 . 8 3} \\
(3.21)\end{array}$ & $\begin{array}{l}\mathbf{1 . 3 0} \\
(4.78)\end{array}$ & $\begin{array}{l}\mathbf{0 . 0 7} \\
(3.00)\end{array}$ & $\begin{array}{l}\mathbf{0 . 2 1} \\
(3.45)\end{array}$ & $\begin{array}{l}\mathbf{0 . 8 3} \\
(3.23)\end{array}$ & $\begin{array}{l}\mathbf{1 . 2 8} \\
(4.81)\end{array}$ \\
\hline & & {$[2.24]$} & [2.53] & {$[3.16]$} & {$[3.81]$} & {$[2.17]$} & {$[2.47]$} & [3.08] & [3.73] \\
\hline & $\bar{R}^{2}$ & $\begin{array}{l}\mathbf{0 . 0 3} \\
(0.00)\end{array}$ & $\begin{array}{l}\mathbf{0 . 0 7} \\
(0.00)\end{array}$ & $\begin{array}{l}\mathbf{0 . 2 6} \\
(0.00)\end{array}$ & $\begin{array}{l}\mathbf{0 . 4 0} \\
(0.00)\end{array}$ & $\begin{array}{l}\mathbf{0 . 0 2} \\
(0.00)\end{array}$ & $\begin{array}{l}\mathbf{0 . 0 7} \\
(0.00)\end{array}$ & $\begin{array}{l}\mathbf{0 . 2 7} \\
(0.00)\end{array}$ & $\begin{array}{l}\mathbf{0 . 4 1} \\
(0.00)\end{array}$ \\
\hline & & {$[0.01]$} & {$[0.04]$} & {$[0.13]$} & {$[0.22]$} & {$[0.01]$} & {$[0.04]$} & {$[0.13]$} & {$[0.21]$} \\
\hline
\end{tabular}

Notes: See separate page with notes to tables. 
Figure 1: The $\widehat{p y}$-ratio and dividend yield (dotted line; right scale). US

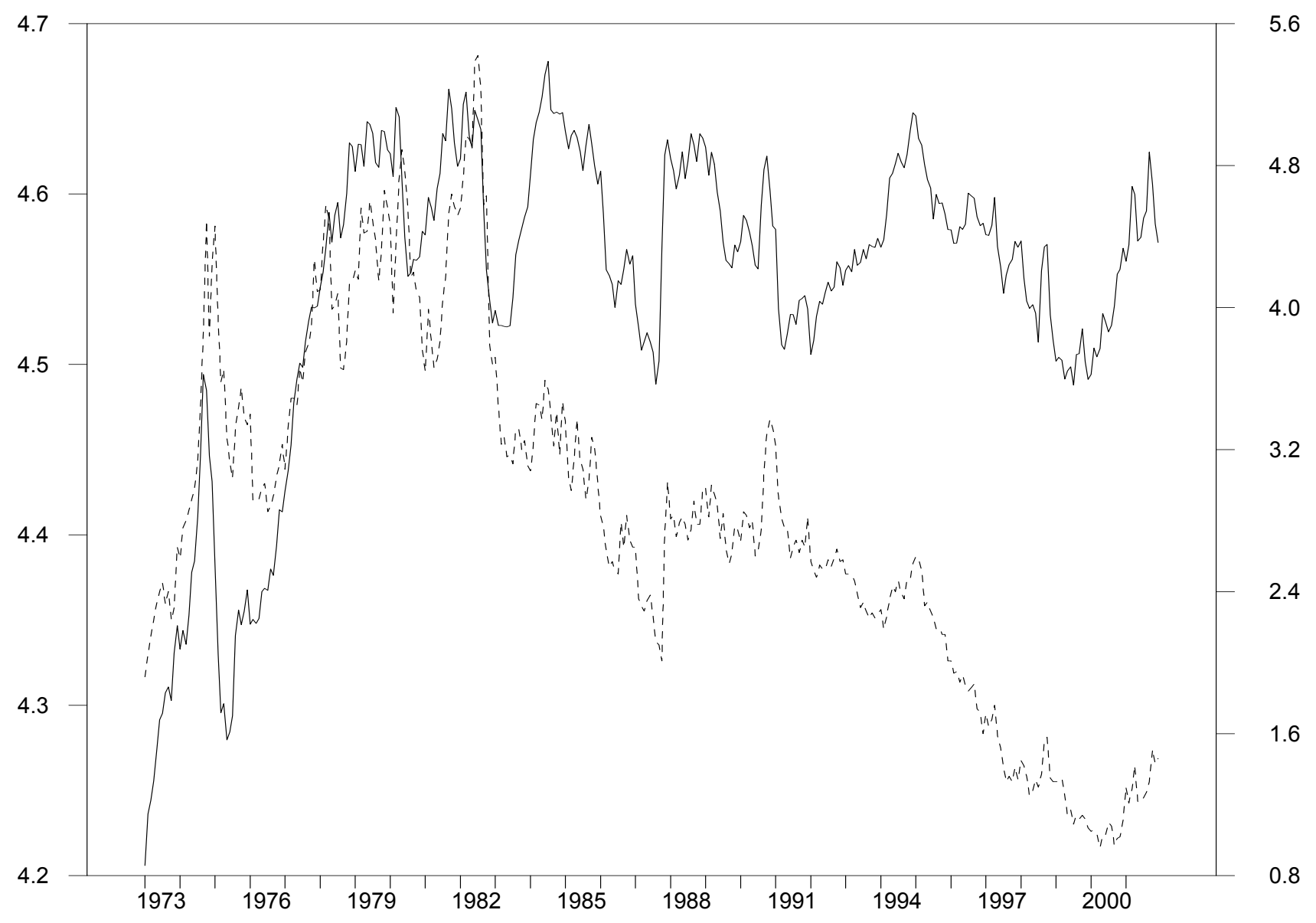




\section{Notes for Tables}

\section{Notes to Table 1:}

The table shows the annualized sample means, the associated annualized standard deviations, and the first-order autocorrelation coefficients $\left(\rho_{1}\right)$ for real returns $(r)$, changes in industrial production $(\Delta y)$, the relative short interest rates $(\mathrm{rrel})$, the dividend yields $(d e)$, and the price-earnings ratios (pe) from 12 OECD countries.

\section{Notes to Table 2:}

The table shows results from tests for cointegration between share prices and real activity. $\lambda_{\max }$ and $\lambda_{\text {Trace }}$ refer to Johansen tests for cointegration based on VAR-models with three lags. The " $-(1 / \widehat{\gamma})$ " column shows the estimated cointegration parameter. The " $\beta^{\prime}=[1,-1]$ " columns report different test statistics from tests of the hypothesis that share prices and real activity cointegrate with a unit coefficient. In the Johansen-based tests for $\beta^{\prime}=[1,-1]$, the null hypothesis is that the series $y_{t}-p_{t}$ is stationary. In the PP and the Horvath \& Watson tests for $\beta^{\prime}=[1,-1]$, the null hypothesis is that the series $y_{t}-p_{t}$ is non-stationary. The " $\widehat{\beta}^{\prime}=[1,-1 / \widehat{\gamma}]$ " columns report test statistics from tests of the null hypothesis that the series $y_{t}-\gamma p_{t}$ is non-stationary, with $\gamma$ given by the cointegration coefficients reported in the " $-(1 / \widehat{\gamma})$ " column. Finally, the summary statistics for the $y_{t}-\gamma p_{t}$ series are shown.

\section{Notes to Table 3:}

The table shows the coefficient estimates from regressions of monthly returns on a constant and the lagged deviations from the estimated price-output ratios ( $\widehat{p y}$-ratios) in the "1" rows, the coefficient estimates from regressions of monthly returns on a constant and the lagged controls only (lagged changes in real activity $\Delta y_{t-1}$, lagged relative interest rates rrel $_{t-1}$, lagged dividend yields $d y_{t-1}$, lagged price-earnings ratios $p e_{t-1}$, and the lagged real returns $r_{t-1}$ ) in the "2" rows, and the coefficient estimates from regressions of monthly returns on a constant, the lagged deviations from the estimated price-output ratios ( $\widehat{p y}$-ratios), and the lagged controls in the "3" rows. The associated $t$-statistics are given in parentheses below coefficient estimates, and the significant estimates (at a ten percentage significance level) are emphasized by being printed in bold type face. The percentages of the variances in the dependent variables explained by the variances of the ex ante observable variables, adjusted for the number of regressors, are given in the $\bar{R}^{2}$ columns (with associated probability values from tests of the joint significance of all the regressors in a given regression in parenthesis below).

\section{Notes to Table 4:}

See notes to Table 3 . The dependent variables are the changes in real activity. 


\section{Notes to Table 5:}

The table shows the $\bar{R}^{2}$ s from regressions of cumulative long-horizon returns (and cumulative changes in real activity) on the $\widehat{p y}$-ratios only, the controls only, and the full model (controls $+\widehat{p y}$-ratios). The cumulative returns are generated by summing the monthly returns. In parentheses below the $\bar{R}^{2}$ s are shown the probability values from Wald tests of the hypothesis that all coefficients except the constant in a regression are equal to zero. The Wald tests adjust for the autocorrelation in the residuals resulting form the use of overlapping cumulative returns.

\section{Notes to Table 6:}

The table shows selected fractiles as well as the means from the simulated distributions of the $\bar{R}^{2}$ s from regressions of real returns on the $\widehat{p y}$-ratios generated under the null hypothesis of no return predictability. The distributions are based on 5000 simulations. The " $\bar{R}^{2}$ " column repeats the actually observed $\bar{R}^{2}$ s reported in Tables 3 and 5 .

\section{Notes to Table 7:}

The table shows the root-mean squared forecast error from predictions of returns and cumulative returns when predicting with the $\widehat{p y}$-ratio in relation to the root-mean squared forecast error from predictions of returns and cumulative returns when predicting with a random walk with drift in the first $U$ column (a value less than one indicates that the forecasts generated from the $\widehat{p y}$-ratio are more precise than those generated from a random walk), the $t$-statistics as based on the Harvey et al. (1997) test that $U$ is equal to one in the $t$-stat column, and the associated $p$-value in the third column. Significant statistics are printed in bold type face. The $d y$ columns show the same three statistics ( $U, t$-statistic, and $p$-value) when predicting with the dividend yields, and the pe columns show the statistics when predicting with the price-earnings ratios.

\section{Notes to Table 8:}

The table shows the regression coefficients $\varphi$ from regressions of monthly MSCI returns and cumulative long-horizon MSCI returns on the $\widehat{p y}$-ratios. The cumulative returns are generated by summing the monthly returns. In parentheses below the $\varphi$ s are shown the Newey-West (1987) autocorrelation and heteroscedasticity corrected $t$-statistics and in squared brackets are shown the 95 percentage fractiles from simulated empirical distributions of the Newey-West (1987) autocorrelation and heteroscedasticity corrected $t$ statistics generated under the null of no predictability. The $\bar{R}^{2}$ s rows show the $\bar{R}^{2}$ s from the regressions. In parentheses below the $\bar{R}^{2}$ s are shown the probability values from test of the hypothesis that the $\varphi$-coefficient is equal to zero and in squared brackets, the 95 percentage fractiles from the simulated empirical distributions of the $\bar{R}^{2}$ s generated under the null of no predictability are shown. 